Canadian

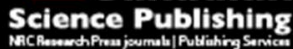

Canadian Geotechnical Journal Revue canadienne de géotechnique

\title{
Clogging of pervious concrete pile caused by soil piping: An approximate experimental study
}

\begin{tabular}{|c|c|}
\hline Journal: & Canadian Geotechnical Journal \\
\hline Manuscript ID & cgj-2017-0238.R3 \\
\hline Manuscript Type: & Article \\
\hline Date Submitted by the Author: & 31-Oct-2017 \\
\hline Complete List of Authors: & $\begin{array}{l}\text { Cui, Xinzhuang; Shandong University, Department of Transportation } \\
\text { Engineering } \\
\text { Zhang, Jiong; School of Civil Engineering, Shandong University, } \\
\text { Chen, Dar Hao; Texas Dept of Transportation, } \\
\text { Li, Shucai; Shandong University, School of Civil Engineering, Shandong } \\
\text { University } \\
\text { Jin, Qing; Shandong University } \\
\text { Zheng, Yingjie; Shandong University } \\
\text { Cui, Sheqiang; School of Civil Engineering, Shandong University, }\end{array}$ \\
\hline $\begin{array}{r}\text { Is the invited manuscript for } \\
\text { consideration in a Special } \\
\text { Issue? : }\end{array}$ & N/A \\
\hline Keyword: & Pervious concrete pile, Clogging, Soil piping, Permeability \\
\hline
\end{tabular}




\section{Clogging of pervious concrete pile caused by soil piping:}

$5 \quad{ }^{1}$ Professor, School of Civil Engineering, Shandong University, Jinan 250061, P.R. China. E-mail:

6 cuixz@sdu.edu.cn

$7 \quad{ }^{2}$ Associate Professor, School of Civil Engineering, Shandong University, Jinan 250061, P.R. China

8 (Corresponding Author). E-mail: jiongzhang@sdu.edu.cn

9

\author{
Xinzhuang Cui ${ }^{1}$, Jiong Zhang ${ }^{2}$, Darhao $\mathrm{Chen}^{3}$, Shucai $\mathrm{Li}^{4}$, Qing Jin ${ }^{5}$, Yingjie Zheng ${ }^{6}$, and Sheqiang

$$
\mathrm{Cui}^{7}
$$

${ }^{3}$ Associate Professor, Texas Department of Transportation, 4203 Bull Creek \#39, Austin, TX 78731, United States. Email: darhao2008@gmail.com

${ }^{4}$ Professor, School of Civil Engineering, Shandong University, Jinan 250061, P.R. China. E-mail:

lishucai@sdu.edu.cn

${ }^{5}$ Lecturer, School of Civil Engineering, Shandong University, Jinan 250061, P.R. China. E-mail: jinqing@sdu.edu.cn

${ }^{6}$ Lecturer, School of Civil Engineering, Shandong University, Jinan 250061, P.R. China. E-mail: zhengyingjie@sdu.edu.cn

${ }^{7}$ Graduate Student, School of Civil Engineering, Shandong University, Jinan 250061, P.R. China. Email: 1914569734@qq.com

\section{An approximate experimental study}




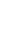

ABSTRACT: Due to their high permeability and high strength, pervious concrete piles (PCPs) can improve the ground bearing capacity. However, clogging of pervious concrete in practice is a potential disadvantage. To investigate the clogging mechanism of PCPs due to sand piping, a series of laboratory simulation tests is conducted on a developed hydraulic conductivity test system. It demonstrates the effects of pervious concrete porosity, grading of fine movable particles, mix ratio of skeleton particles to movable particles, relative density of soil, and distance between PCPs on PCP clogging. The experimental test results show that the hydraulic conductivity of PCP decreases for approximately $70 \mathrm{~min}$ and then becomes relatively stable. In addition, it is observed that PCP clogging rarely occurs in cases of low pervious concrete porosity, small movable sand particle size, high sand relative density, and large pile distance. The results also show that measurement of electrical conductivity can be an alternative method of hydraulic conductivity measurement. Based on the test results, preliminary clogging models are proposed.

KEYWORDS: Pervious concrete pile; Clogging; Soil piping; Permeability

7.

(1)

(1)




\section{Introduction}

In recent years, composite foundation technologies have been widely used to enhance the bearing capacity of foundations and reduce the settlement and liquefaction potential of the ground (Ariyarathne et al. 2013; Haldar and Babu 2010; Shen and Xu 2011). Vertical reinforcements of composite foundations may be divided into granular piles and rigid piles (Shen et al. 2013, 2016, 2017). Granular piles have been widely used in engineering, as they can accelerate the rate of consolidation and reduce the liquefaction potential of a sand or silt foundation (Hughes and Withers 1974; Lee and Pande 1998; Ferreira Pinto and Delgado Rodrigues 2008; Poorooshasb and Meyerhof 1997). However, the stiffness and strength of granular piles are low and are greatly related to the confining pressure of the surrounding soil (Guetif et al. 2007). When soft clay, organic soil, or peat soil is subjected to vertical loading and granular piles are applied, the shallow part of granular piles is prone to fail by bulging into the surrounding soil. This limits their use in soft clay, organic soil, or peat soil (Suleiman et al. 2014).

When subjected to lateral loading, granular piles fail in direct shear at the location of loading or along the slope failure surface ( $\mathrm{Ni}$ et al. 2016). Although rigid piles, such as low-grade concrete piles and cement fly-ash gravel piles, can overcome the weak bonding problem of granular piles (Sariosseiri and Muhunthan 2009; Le Hello and Villard 2009; Zheng et al. 2008; Jia et al. 2011), they have poor permeability and induce a small foundation consolidation rate.

Recently, an innovative ground improvement method that utilizes pervious concrete piles (PCPs) was proposed by Suleiman et al. (2011), who developed an installation process and a creative method to investigate the soil-structure interaction under vertical and lateral loadings (Suleiman et al. 2014; Lin et al. 2016; Ni et al. 2016). Pervious concrete, also referred to as porous concrete, is a mixture of Portland cement, gap-graded aggregate, and water with or without a small amount of fine aggregate. 
Many connective pores exist within the aggregate skeleton. Generally, the porosity of pervious concrete is between $15 \%$ and $25 \%$, and the hydraulic conductivity is typically between 2 and $6 \mathrm{~mm} / \mathrm{s}$ but can be as high as $10 \mathrm{~mm} / \mathrm{s}$ (Tennis et al. 2004; Montes et al. 2005; Luck et al. 2006). Because of its high hydraulic conductivity, pervious concrete can also provide a compressive strength between 3.5 and $28 \mathrm{MPa}$ (Schlüter and Jefferies 2002). Therefore, piles made of pervious concrete offer fast drainage and have a high bearing capacity, i.e., PCPs have the advantages of both granular piles and rigid piles (Zhang et al. 2016). The fast drainage capacity of PCPs could not only accelerate the dissipation of excess pore water pressure and subsoil consolidation but also reduce the post-construction settlement of an upper construction, such as a road embankment. However, fine particles from the soil matrix can progressively get into a PCP via the seepage flow induced by excess pore water pressure and clogged PCP pores, leading to a gradual reduction of the PCP hydraulic conductivity.

Clogging is a common phenomenon that has occurred in many drainage projects. Several studies on the clogging of permeable materials such as gravel and pervious concrete have been performed (Jimenez et al. 1990; Kayhanian et al. 2012; Deo et al. 2010; Neithalath et al. 2006; Haselbach 2006; Haselbach et al. 2010; Reddi et al. 2000; Reddi et al. 2005). The variation of the hydraulic conductivity of pervious concrete pavement with time was studied by Jimenez and Perez (1990). Kayhanian et al. (2012) assessed the clogging of pervious concrete pavements in parking lots via the falling head method using a National Center for Asphalt Technology device in the field. To evaluate the contribution of pores to clogging susceptibility, Deo et al. (2010) developed a falling head hydraulic conductivity cell to simulate clogging cycles. For each clogging cycle, $25 \mathrm{~g}$ of sand was initially spread evenly over the specimen surface, and a hydraulic conductivity test was conducted at 
the end. Such experiments were repeated until further sand additions did not result in noticeable changes in hydraulic conductivity. In addition to the process of clogging development, clogging criteria have also been studied (Ghidaglia et al. 1996; Narayan et al. 1997). Tan et al. (2003) derived an empirical theoretical formulation from the Kozeny-Carman equation to predict the reduction in hydraulic conductivity of a permeable road base.

Similar to PCPs, prefabricated vertical drains (PVDs) are used to accelerate the consolidation process and rapidly increase the strength and stiffness of soil. Many investigations have demonstrated that fine particles in the soil could be entrapped within the fibers of a filter, i.e., the geotextile, surrounding a PVD. If the pores of a filter sleeve become clogged, the discharge capacity of the PVD decreases, and the consolidation process is consequently impeded (Rollin and Lombard 1988; Basu and Madhav 2000).

Currently, few investigations on PCP clogging have been reported (Lin et al. 2016), although the issue of clogging has been considered since the technique was first proposed. There are two possible reasons for PCP clogging. First, during the installation of a PCP via vibratory construction methods, the natural subsoil adjacent to the pile may experience local liquefaction due to strong vibration induced by the migration of excess pore pressure fine soil particles into the piles during pervious concrete hardening (Zou et al. 2010; Adalier and Elgamal 2004). Second, clogging can occur during the operation period, the mechanism of which is shown in Fig. 1. The upper load can cause excess pore water pressure to develop in the layer where soil piping can occur. Because of the poor drainage capacity of the upper and lower clay layers, the excess pore water pressure is mainly dissipated by the permeable piles. For a non-cohesive soil, a micro bridge network can form near the contact surface with contact piping, as shown in Fig. 2 (Rollin and Lombard 1988). At first, large particles are stopped 
111 at the contact surface. In turn, these particles retain smaller particles to form a dense filter zone, and

112 this process continues until the soil stabilizes. The fine particles in the bridging network migrate into

113 the drain. Once soil piping occurs, the permeable piles may become clogged by soil particles

114 (Boulanger et al. 1998).

115 This study focuses on an approximate experimental simulation of PCP clogging caused by soil

116 piping during the operation period. A physical clogging simulation system combined with hydraulic

117 conductivity and electrical conductivity measurements of pervious concrete is developed. A series of

118 laboratory simulation tests is conducted using this system to demonstrate the effects of PCP porosity,

119 grading of fine movable soil particles, mix ratio of skeleton soil particles to movable soil particles,

120 relative soil density, and distance between PCPs on clogging. The clogging mechanism of a soil-PCP

121 system is investigated, and a preliminary clogging model is proposed.

122 Development of PCP clogging simulation system

123 No standard test procedure for measuring and evaluating the hydraulic conductivity of pervious

124 concrete caused by soil piping is available. The existing testing apparatuses cannot constantly record

125 the continuous variation in hydraulic conductivity of pervious concrete specimens. To investigate the

126 reduction in PCP hydraulic conductivity due to clogging caused by soil piping, a simulation cell that

127 can continually record the hydraulic conductivity changes is necessary. Based on the simulation

128 system mentioned in a previous study (Cui et al. 2016), a system is designed (Fig. 3). To

129 approximately simulate the real situation in the composite foundation (as shown in Fig. 4), the sand

130 column and pervious concrete specimen are indicated as the zone in the red frame shown in the figure

131 after a clockwise rotation of $90^{\circ}$. The height of the pervious concrete specimen is equal to the radius of

132 the pervious concrete pile, and the height of the sand column is equal to half of the pile distance minus 
the pile radius. The downward flow is used in this study for two reasons. First, it is believed that the downward flow simulates the most adverse conditions, because in this case, gravity on the particles acts in the same direction as the seepage or drag force (Lafleur 1984). Second, migrations of gravity-driven particles are rather weak compared with migrations of particles induced by seepage forces (Tomlinson and Vaid 2000). The functions of the developed simulation system mainly include the following: (1) avoiding leakage on the pervious concrete specimen sidewalls during the hydraulic conductivity tests by using a waterproof daub and flexible rubber cushion (Cui et al. 2015); (2) simulating the PCP clogging caused by soil piping; (3) recording the continuous variation in hydraulic conductivities for both the pervious concrete and soil column; and (4) simultaneously monitoring the change in pervious concrete electrical conductivity during the clogging process. All the measurement modules employed have been calibrated.

\section{Continuous recording of hydraulic conductivity changes during the clogging process}

As shown in Fig. 3, two water pressure sensors and an ultrasonic velocity meter are installed to record the change in hydraulic conductivity of both the pervious concrete and soil column during the clogging process in real time. All the sensors are connected to a computer by an A/D converter. To measure the hydraulic conductivity of pervious concrete, the head loss between the upper and bottom surfaces of a specimen is acquired from the water pressure sensors, and the velocity of the water in the pipes is measured by the ultrasonic velocity meter. The hydraulic conductivity of the specimen is calculated through the method presented by Cui et al. (2015).

\section{Continuous recording of change in electrical conductivity during clogging process}

Electrical conductivity has already been used to characterize the porosity of soil, rock, and concrete (Neithalath et al. 2006; Samouëlian et al. 2005; Turesson 2006; Zhang et al. 2014). The electrical 
conductivity and hydraulic conductivity are employed together to characterize the clogging process of pervious concrete.

Because fresh water is not a suitable conductor of electricity to form a closed circuit in the saturated pervious concrete specimen, $10 \%$ ( $\mathrm{Li}$ et al. 2014) $\mathrm{NaCl}$ solution with a density of $1.070 \mathrm{~g} / \mathrm{cm}^{3}$ is used as the circulating fluid in the continuous physical simulation system for clogging. Therefore, the density of salt water is used in the calculation of water head loss. As shown in Fig. 3, two copper meshes (13) are placed at both sides of the specimen as electrodes and are connected to an AC power (15) of $12 \mathrm{~V}$. The pore size of the copper meshes is $10 \mathrm{~mm}$. The changes in current and power are measured continually by a multimeter (14) connected to the computer (18) via the A/D converter (17).

Therefore, the electrical conductivity of the pervious concrete specimen can be calculated as follows:

$$
\sigma=\frac{A^{2}}{W} \frac{L_{p}}{S}
$$

where $\sigma$ is the electrical conductivity, $W$ is the power, $A$ is the current, $S$ is the cross-sectional area of the specimen, and $L_{p}$ is the length of specimen.

\section{Test materials}

\section{Pervious concrete}

Pervious concrete mixtures are prepared using ordinary Portland cement and coarse aggregates. The aggregates are composed of limestone rubble with particle sizes ranging from $4.75 \mathrm{~mm}$ to $9.5 \mathrm{~mm}$. The physical indexes are listed in Table 1. A sulphamate series superplasticizer is used to decrease water usage. Its dosage contributes $0.8 \%$ of the cement mass. Three mixtures are prepared for three target porosities: $15 \%, 20 \%$, and $25 \%$. The mix design method used in this study is the same as that presented by Cui et al. (2015). The mix proportions of pervious concrete per cubic meter are given in Table 2 . 
The mixtures are prepared using a laboratory mixer, and specimens are cast in $\phi 100 \mathrm{~mm} \times 100 \mathrm{~mm}$ cylindrical molds and demolded after $24 \mathrm{~h}$. All specimens are placed in a standard curing room for 28 days. When the porosity values are $15 \%, 20 \%$, and $25 \%$, the average values of compressive strength are 20.7, 18.1, and 14.3 MPa, and the average initial hydraulic conductivities are $0.3,0.5$, and $1.1 \mathrm{~cm} / \mathrm{s}$ respectively. The properties of pervious concrete are similar to the published results (Suleiman et al. 2014; Ni et al. 2016).

\section{Sand column}

The sand column in which piping can occur is a mixture of skeleton particles and movable particles (Tables 3 and 4). The skeleton is composed of coarse gravel with particle sizes ranging from $4.75 \mathrm{~mm}$ to $9.5 \mathrm{~mm}$. The movable particles include four types of fine sand with particle sizes ranging from 0.3 $\mathrm{mm}$ to $4.75 \mathrm{~mm}$. Based on the criterion given by the Nanjing Hydraulic Research Institute of China (Liu 2006), piping can occur for all mixtures.

\section{Test procedure and scheme}

\section{Test procedure}

With the advantage of a newly developed device, a clogging test of pervious concrete is carried out according to the following procedure:

1) The pervious concrete specimens, after curing for 28 days in a standard curing room, are first submerged in $10 \% \mathrm{NaCl}$ solution for $24 \mathrm{~h}$. After the surface of a specimen is wiped, petroleum jelly is daubed on the side and the specimen is covered with a flexible rubber cushion ( 2 in Fig. 3). Next, specimens are installed in a polymethyl methacrylate (PMMA) sleeve (3 in Fig. 3) and mounting bolts are screwed in. Then, the sand mixture is added layer by layer above the pervious concrete specimen. 
197 To ensure uniformity, the thickness of a single layer is set approximately $20 \mathrm{~mm}$ and each layer is 198 compacted manually based on its relative density (Fig. 3).

199

2) A $10 \% \mathrm{NaCl}$ solution is prepared as the circulating fluid. The valve (7 in Fig. 3 ) is turned off while the pump (11 in Fig. 3) is turned on. Fluid is dumped evenly into the PMMA sleeve and the water level in the sleeve is determined based on the height of the outflow (5 in Fig. 3). The sand and pervious concrete are immersed in the circulating fluid for $1 \mathrm{~h}$ so that the influence of bubbles in the sand or specimen can be minimized.

3) The valve (7 in Fig. 3) is turned on; fluid infiltrates through the pervious concrete and is discharged ( 8 in Fig. 3). Meanwhile, the AC power (15 in Fig. 3) is turned on to apply $12 \mathrm{~V}$ to the wire netting, which covers both ends of the specimen. Simultaneously, the sensors start recording the water pressure (by 16 in Fig. 3), flow rate (by 12 in Fig. 3), and electric current and power (by 14 in Fig. 3).

4) The clogging test continues until the flow rate of the specimen becomes relatively stable (the process lasts approximately $70 \mathrm{~min})$.

5) After the test ends, the sand above the specimen is taken out layer by layer in increments of 90 $\mathrm{mm}$. The sand is then dried and sieved to analyze the change in gradation.

\section{Test cases}

In this research, characterization methods are used to investigate the influence of pile distance, porosity, movable particle size, sand mixing proportion, and relative density on clogging. Three sand column heights are selected, namely $270 \mathrm{~mm}, 360 \mathrm{~mm}$, and $450 \mathrm{~mm}$ (Cases 10, 3, and 12 in Table 5, respectively), i.e., the half pile distances are $370,460,550 \mathrm{~mm}$ respectively. Therefore, the values of 
area replacement ratios are $0.06,0.04$, and 0.03 respectively. The height of the outflow controls the pore pressure in the composite foundation. Because the excess pore water pressure difference in the composite foundation of the Yellow River Delta is approximately $5 \mathrm{kPa}$ between the subsoil at the center of two piles and the PCP at a depth of $5.5 \mathrm{~m}$ (Zhang et al. 2016), the height of the water level in this study is kept at $500 \mathrm{~mm}$ with equal proportion in real condition. The porosities of the specimens are set as $15 \%, 20 \%$, and $25 \%$ (Cases 1,2 , and 3 in Table 5, respectively). M1, M2, M3, and M4 (Cases 4, 3, 5, and 6 in Table 5, respectively) are used as movable particles. The mixing proportions of movable and skeleton particles of 1:3, 1:4, and 1:5 are tested (Cases 7, 3, and 8 in Table 5, respectively). Three relative densities are selected, namely $0.3,0.6$, and 0.9 (Cases 9, 3, and 10 in Table 5, respectively). Cases 13 to 20 are the orthogonal test design supplement. For each case, three samples are tested. The initial hydraulic conductivity values of sand columns are also given in Table 5.

\section{Experimental results and analysis}

\section{Influence of pervious concrete porosity on clogging}

The porosity of the pervious concrete specimen is set as the independent variable in this test. The time history curves of the average normalized hydraulic conductivities (NP, acquired by dividing the instantaneous hydraulic conductivity by the initial value) of the sand columns are shown in Fig. 5(a).

For all the three samples, the hydraulic conductivities of the sand columns decrease rapidly in the initial test phase. Twenty minutes later, the change in hydraulic conductivity slows down and becomes relatively stable after $40 \mathrm{~min}$. After $70 \mathrm{~min}$, the decrease in hydraulic conductivity is more obvious because the porosity is smaller. For specimens with porosity values of $15 \%, 20 \%$, and $25 \%$, the final average hydraulic conductivities are $0.28,0.46$, and 0.51 times the initial values, respectively. The 
presence of noise in the curves are caused by the following. First, injecting water into the physical simulation system causes pressure oscillation on the specimen surface. Second, the environment and electrical circuits can cause noise.

When piping occurs, large particles are initially trapped at the contact surface. Then these particles retain small particles, forming a dense filter zone. This process continues until the soil is stabilized. The stability of the soil hydraulic conductivity in Fig. 5(a) depends on the stabilities of the soil particles. On one hand, the dense filter zone decreases the hydraulic conductivity of the soil. On the other hand, the transport of soil particles from the soil column increases the soil hydraulic conductivity. The average soil hydraulic conductivity after stabilization is a comprehensive reflection of two contradictory aspects. A specimen with large porosity has a greater seepage flow velocity, which can form a large bridging network and reduce the filter zone. Therefore, the average soil hydraulic conductivity will increase (as shown in Fig. 5(a)).

Fig. 5(b) shows the NP time history curves of pervious concrete specimens with different porosities. Generally, there is no obvious change in the hydraulic conductivity of pervious concrete at the initial phase. The decline starts approximately $20 \mathrm{~min}$ later, the same time at which the hydraulic conductivity of the sand column becomes relatively stable (Fig. 5(a)). This phenomenon occurs because movable particles in sand require a certain amount of time to reach the interface between the sand column and the pervious concrete specimen. They later migrate into the pore structure via seepage flow and result in clogging. Forty minutes after the test begins, the slope of the hydraulic conductivity decreases. After $70 \mathrm{~min}$, the hydraulic conductivity of pervious concrete becomes stable. However, for the specimen with porosity of $20 \%$, the NP value increases at the beginning of the measurement. This could be the result of the undersaturation and the presence of bubbles. Along with 
the flow, bubbles that are driven out of the system could cause an increase in the hydraulic conductivity.

Fig. 5(c) shows the normalized electrical conductivity (NEC, obtained by dividing the instantaneous electrical conductivity by the initial value) time history curves for specimens with different porosities. The variation tendency of the electrical conductivity is generally the same as that of the hydraulic conductivity. Compared with the measurement of permeability, electrical conductivity measurement is much more convenient. Therefore, the measurement of electrical conductivity can be an alternative method of hydraulic conductivity measurement. According to Figs. 5(b) and 5(c), specimens with large porosity are more easily clogged. This phenomenon occurs because the pore size and seepage velocity are larger in specimens with large porosity. Thus, more particles can migrate into the pore system via seepage flow, which increase the possibility of particles clogging the narrow part of the pathway.

After the tests, the sand layer is removed in layers (each layer is $90 \mathrm{~mm}$ high), and then dried and sieved to analyze the change in gradation (as indicated in Table 6). The proportion of fine particles in the bottom layer is greater than that in the upper layers for Cases 1-3. This is because movable particles carried via seepage flow move to the sand-pervious concrete interface. With increasing pervious concrete porosity, the proportion of movable particles in the bottom layer increases as well.

\section{Influence of movable particle size on clogging}

Three types of sand mixtures are used in investigating the influence of movable particle size on clogging. The movable particles are denoted as $\mathrm{M}$ and the skeleton particles are denoted as S (Table 5). The proportion of skeleton to movable particles is $4: 1$, the relative density is 0.6 , the porosity of pervious concrete is $25 \%$, and the height of the sand column is $360 \mathrm{~mm}$. 
The time history curves of the average NP of sand columns with different movable particles are shown in Fig. 6(a). When the clogging processes reach equilibrium, the average hydraulic conductivity of the sand column clearly decreases in M1 (Case 4) and M2 (Case 3) with movable particles, particularly for Case 4 because the M1 movable particles in Case 4 are well-graded sand. Some of the large particles and fine particles in M1 can together more easily form a stable micro bridge network with seepage flow, as shown in Fig. 7(a). The micro bridge increases the resistance to movement of fine particles and accelerates the formation of the filter zone. For M3 (Case 5) and M4 (Case 6), the hydraulic conductivities of the sand columns increase during the test. This phenomenon occurs because these two types of movable particles mainly comprise fine sand that has difficulty in forming the bridge network. A mass of fine sand particles can pass through the sand-pervious concrete interface and migrate into the pores of the pervious concrete (Fig. 7(b)).

Fig. 6(b) shows the NP time history curves of pervious concrete specimens for different movable particles. The hydraulic conductivities of pervious concrete are also different for the four cases. In the initial test stage, the hydraulic conductivities decrease quickly for M3 and M4. Different from M1 and M2, the movable particles in M3 and M4 are mainly composed of fine particles. The fine particles can be quickly transported into the pervious concrete after the test starts and partial inner pores in the pervious concrete are clogged rapidly. As observed, the final hydraulic conductivity of pervious concrete for Case 6 (M4) is the largest. The reason for this is that M4 particles can easily pass through most of the pervious concrete pore channels.

Table 7 presents the particle size distributions of each sand layer after completion of the tests. The proportion of fine particles (less than $0.6 \mathrm{~mm}$ ) in the bottom layer is greater than that in the upper layers for Cases 3, 4, 5, and 6. Note that for Case 4 (M1), because it is a well-graded mixture with 
sizes between 1.18 and $4.75 \mathrm{~mm}$, their incipient motion is more difficult compared with the fine movable particles. Therefore, most of them migrate slowly, resulting in a higher proportion at the top and lower proportion at the bottom.

\section{Influence of sand mixing proportion on clogging}

Three mixing proportions of movable and skeleton particles are used in this test. The relative density of the sand mixture is 0.6 , the porosity of the pervious concrete is $25 \%$, and the height of the sand column is $360 \mathrm{~mm}$. The NP time history curves of the sand column and pervious concrete specimen are shown in Fig. 8.

As Fig. 8(a) shows, when the change in hydraulic conductivity becomes stable, the hydraulic conductivity of the sand column decreases as the mixing proportion of the movable particles decreases. This is because the resistance to movement decreases when there are less movable particles filling in the pores of the skeleton particles. Therefore, it is easier for movable particles to reach the sandpervious concrete interface to form the dense filter zone, which decreases the hydraulic conductivity of the sand column. This supposition is supported by Table 8 and Fig. 9. Table 8 presents the particle size distributions in the sand layers after the completion of testing and Fig. 9 shows the proportions of movable particles. As illustrated in Fig. 9, the proportion of movable particles after testing is distributed more unevenly in the sand column as the mixing proportion of movable particles decreases.

As shown in Fig. 8(b), the final hydraulic conductivities of pervious concrete for Cases 3, 7, and 8 are relatively similar although the clogging processes are different. The probable reason is that the quantity of sand clogging the pervious concrete can be sufficiently provided by the sand column in these three cases. Moreover, the movable particles (clogging source) in these three cases are of the 
same type. Under these circumstances, the seepage velocity is a consequential factor in controlling the clogging. As mentioned above, a small mixing proportion of movable particles can cause a large reduction in the hydraulic conductivity of the sand column and a low seepage velocity, which prolong the clogging process in pervious concrete.

\section{Influence of relative density of sand on clogging}

Three samples of distinct relative density are applied in the test. The porosity of the pervious concrete is $25 \%$, M2-S-14 sand is used, and the height of the sand column is $360 \mathrm{~mm}$. The NP time history curves of the sand column and pervious concrete specimen are shown in Fig. 10, respectively.

As Fig. 10(a) shows, the stable normalized hydraulic conductivity of the sand column increases as the relative density increases. When the relative density increases, the particles become more firmly packed and the number of gaps between particles decreases. Therefore, it is more difficult for movable particles to be carried off by the seepage flow, less movable particles are transported to the sandpervious concrete interface, and the decrease in hydraulic conductivity is smaller. Table 9 presents the evidence showing that the content of movable particles varies from $14.97 \%$ to $23.05 \%$ for loose sand, while for dense packed sand, it varies from $17.82 \%$ to $21.00 \%$.

As shown in Fig. 10(b), the pervious concrete in Case 3 and Case 9 experiences almost the same reduction in hydraulic conductivity, while that in Case 10 remains nearly unchanged. As analyzed above, fewer movable particles are transported to the sand-pervious concrete interface for sand with a large relative density. Thus, fewer particles can enter and clog the pores of PCPs. Case 3 and Case 9 both provide enough movable particles to cause clogging, while the particle holding capacity for pervious concrete is relatively limited. Therefore, they both exhibit the same clogging effect after the hydraulic conductivity becomes stable. 


\section{Influence of sand column height on clogging}

Sand column heights of $270 \mathrm{~mm}, 360 \mathrm{~mm}$, and $450 \mathrm{~mm}$ are used to investigate the influence of sand column height on clogging. The porosity of the pervious concrete is $25 \%$, M2-S-14 sand is used, and the relative density is 0.6 . The NP time history curves of the sand column and pervious concrete specimen are shown in Fig. 11, respectively.

As Fig. 11(a) shows, when the clogging processes reach equilibrium, the decrease in hydraulic conductivity of the sand column is most noticeable in Case 12 and least noticeable in Case 11. Based on Darcy's law, the seepage velocity has a negative correlation with the sand column height. Therefore, Case 11 has the largest hydraulic gradient, and the movable particles are transported to the interface at the highest speed via seepage flow. The most rapid decrease in hydraulic conductivity of the sand column in Case 11 occurs at the beginning of the test. However, Case 11 has the lowest quantity of movable particles that can be transported to the sand-pervious concrete interface, and the reduction in hydraulic conductivity is limited. The situation in Case 12 is the opposite of that in Case 11. As shown in Table 10, Case 12 has the largest number of movable particles that can accumulate in the bottom layer.

Fig. 11(b) shows that the hydraulic conductivity decreases least for the case with a sand column height of $450 \mathrm{~mm}$. Case 12 has the smallest hydraulic gradient because it has the maximum height. Therefore, the seepage velocity is relatively small, and particles experience more difficulty in getting into the pores of the pervious concrete via seepage flow.

\section{Clogging model of pervious concrete}

The Kozeny-Carman equation forms the basis for deriving the empirical model used to predict the deterioration in hydraulic conductivity of pervious concrete due to clogging. Several researchers have 
used the same equation to study similar phenomena. Blazejeski and Sadzide (1997) used the KozenyCarman equation to study the influence of decreasing porosity on sand hydraulic conductivity. Wu and Huang (2000) used this equation as a basis for deriving their theoretical model to study the effects of sediment intrusion into gravel beds. Tan et al. (2003) derived an empirical theoretical formulation from the same equation to predict the reduction in hydraulic conductivity of permeable bases.

A decreased hydraulic conductivity due to clogging can be represented as a function of the initial hydraulic conductivity, porosity, and specific deposit of clogging material (Tan et al. 2003):

$$
k=k_{0} \frac{(1-P)^{2}}{P^{3}} \frac{(P-\alpha \sigma)^{3}}{[1-(P-\alpha \sigma)]^{2}}
$$

where $k$ is the hydraulic conductivity of a clogged pervious concrete specimen, $k_{0}$ is the initial hydraulic conductivity of the specimen, $P$ is the porosity of the specimen, $\sigma$ is the specific deposit, which is the volume of sediment deposit divided by the bulk volume of the pervious concrete specimen, and $\alpha$ is an empirical coefficient.

Eq. (2) is a modified version of Wu and Huang's model (Wu and Huang 2000), which was used by Tan et al. (2003) to predict the reduction in hydraulic conductivity of permeable bases. From then on, many studies (Haselbach et al. 2006; Deo et al. 2010) began to use the coefficient $\alpha$ for indicating the rate of deterioration in permeability. The value of $\alpha$ also indicates the rate of deterioration of hydraulic conductivity. A high value of $\alpha$ implies a more rapid decrease in hydraulic conductivity. Therefore, $\alpha$ can be used as a means of evaluating the rate of deterioration and predicting the clogging effects. When the clogging particles completely fill up the entire void space within the pervious concrete, $\alpha$ is taken as 1 (Tan et al. 2003).

The values of the coefficient $\alpha$ can be calculated using Eq. (2). Table 11 presents the values of coefficient $\alpha$ for various cases at the end of each test. 
Table 11 shows that when the specimens are clogged with sand, the $\alpha$ values are approximately between 2.7 and 6.0. Wu and Huang (2000) proposed that the depositional patterns of particles in a gravel matrix are governed by the gravel-sediment size ratio and the seepage flow rate. In this study, to analyze the value of $\alpha$ under different testing conditions, five dimensionless variables are used to represent the governing factors, namely the porosity of pervious concrete $P$, dimensionless height of the sand column $H$ (the height of the sand column divided by the height of the pervious concrete specimen), relative density of the sand mixture $D_{\mathrm{r}}$, aggregate-sediment size ratio $R_{\mathrm{s}}=D_{15} / d_{85}$, and coefficient of uniformity of the clogging material $C_{\mathrm{u}}$.

The gravel-sediment size ratio $D_{15} / d_{85}$ in the study of $\mathrm{Wu}$ and Huang (2000) is easy to obtain. However, in this study, because the aggregates in pervious concrete specimens are coated with the hydration products of cement and water, the sizes of the solid grains "expand," and the clogging process can change. Therefore, the expansion of the solid grain volume should be considered. The volumes of solid grains of pervious concrete specimens contain the volumes of the aggregate and the hydration product coating layer. The volume of the hydration product coating layer varies with the porosity of the specimen. The hydration product-induced volume expansion ratio of aggregates can be defined as the volume of solid pervious concrete divided by the volume of aggregates:

$$
R_{\mathrm{v}}=\frac{(1-P)}{V_{\mathrm{a}}}=\frac{(1-P) \rho_{\mathrm{a}}}{m_{\mathrm{a}}}
$$

where $R_{\mathrm{v}}$ is the volume expansion ratio, which, in the case of no hydration product coating layer on the aggregate, is taken as $1 ; V_{\mathrm{a}}$ is the volume of aggregates per cubic meter of concrete, $m_{\mathrm{a}}$ is the mass of aggregates per cubic meter of concrete, $\rho_{\mathrm{a}}$ is the density of the aggregates, and $P$ is the pervious concrete porosity.

Thus, the expansion ratio of the aggregate equivalent diameter $R_{\mathrm{d}}$ is 


$$
R_{\mathrm{d}}=\sqrt[3]{R_{\mathrm{v}}}
$$

413 The equivalent characteristic sizes of solid grains (aggregate with the hydration product coating 414 layer) in pervious concrete are calculated using Eq. (5) and given in Table 12.

$$
D_{15}=D_{15}{ }^{\prime} R_{\mathrm{d}}
$$

where $D_{15}{ }^{\prime}$ is the equivalent characteristic size of aggregate used in the preparation of pervious concrete.

417 The characteristic sizes of clogging materials are listed in Table 13. After obtaining the equivalent $D_{15}$ of the aggregate and $d_{85}$ of the sediment, the aggregate-sediment size ratio $R_{\mathrm{s}}$ can be calculated, as indicated in Table 11.

Five dimensionless variables are given in Table 11. To reflect the influence of each factor, the multivariate nonlinear fitting was used. After comparisons, the multiparameter power function model is found to fit well with the data. Wu and Huang (2000) also used this type of fitting model with 3 dimensionless variables to study the effects of sediment intrusion into gravel beds. The relationship of the coefficient $\alpha$ with the five dimensionless variables is obtained, as indicated in Eq. (6), with $r^{2}=$ 0.87 ( $r$ is the correlation coefficient).

$$
\alpha=P^{0.08} H^{-0.03} D_{\mathrm{r}}{ }^{-0.92} R_{\mathrm{s}}{ }^{-0.03} C_{\mathrm{u}}{ }^{0.44}
$$

Eq. (6) indicates that the influences of pervious concrete porosity, piles distance, and aggregate-sediment size ratio on the coefficient $\alpha$ have slight differences (the powers of $P, H$, and $R_{\mathrm{s}}$ sand and the coefficient of uniformity have major influence on the coefficient $\alpha$ (the power of $D_{\mathrm{r}}$ is -0.92 , and that of $C_{\mathrm{u}}$ is 0.44 ). Fig. 12 shows that the regression equation is validated by the measured data. 
In view of Terzaghi's filter criterion (Terzaghi 1929), for cases in which $R_{\mathrm{s}}=D_{15} / d_{85}<4$, the physical implication of a small $R_{\mathrm{s}}$ is that the risk of soil piping through the granular filter is reduced. This implication indicates that if the clogging particle sizes are larger relative to the fine aggregate sizes within the specimen, there is a higher tendency for the clogging particles to be retained on the surface of the pervious concrete specimen, e.g., the clogging materials in Case 4 have an $R_{\mathrm{S}}$ of 3.41 , and most sediments in this case are retained on the surface of the pervious concrete.

Meanwhile, for cases with very fine clogging materials, the amount of clogging decreases, e.g., the clogging of fine sediment in Case 6 is the least serious among four cases (Case 3-6), although Case 6 has the largest $R_{\mathrm{S}}$ of 28.25, as shown in Fig. 9. Therefore, the relation between $R_{\mathrm{S}}$ and the coefficient $\alpha$ is complex when the range of $R_{s}$ is greater than 4. Further research regarding the influence of $R_{\mathrm{s}}$ on the coefficient $\alpha$ is required.

The coefficient $\alpha$ of the stable stage is a characteristic resulting from the clogging process that depends on five variables. Using Eq. (2) and (6), the hydraulic conductivity reduction of a pervious concrete pile after clogging can be estimated. However, because the regression is based on experimental data, the applicability of Eq. (6) outside the range of tests is unwarranted (applicable range: $0.15<P<0.25,3<H<5,0.3<D_{\mathrm{r}}<0.9,3.41<R_{\mathrm{S}}<28.25$, and $\left.10.16<C_{\mathrm{u}}<33.73\right)$.

\section{Clogging model of sand column}

The seepage path of fluid in soil is shortened by the installation of pervious piles, and the dissipation of the excess pore water pressure is accelerated. However, when water moves toward the pervious concrete piles, it must first pass through the surrounding soil. If the hydraulic conductivity of soil is reduced and blocked, then the access to the pile is also blocked. The drainage capacity of pile and soil composite foundation will reduce. The consolidation rate of soil will then decrease. Therefore, the 
454

surrounding soil is also considered in the test. To approximately predict the hydraulic conductivity of the soil between PCPs due to clogging, an empirical equation similar to Eq. (6) is derived to predict the variation in hydraulic conductivity of the sand column above the pervious concrete specimen. Via the regression analysis method, the relationship between the variation in hydraulic conductivity and the five dimensionless variables given in Table 14 is obtained, as indicated in Eq. (7), with $r^{2}=0.95$ ( $r$ is the correlation coefficient).

$$
\frac{k_{s}}{k_{s 0}}=P^{0.46} H^{-1.51} D_{\mathrm{r}}^{0.43} R_{\mathrm{s}}^{0.40} C_{\mathrm{u}}^{0.56}
$$

where $k_{\mathrm{s}}$ is the hydraulic conductivity of the clogged sand column and $k_{\mathrm{s} 0}$ is the initial hydraulic conductivity of the sand column.

Fig. 13 shows the fitting result of the regression equation. Eq. (7) indicates that the influences of the pervious concrete porosity, sand relative density, aggregate-sediment size ratio, and coefficient of uniformity of the clogging material on the reduction in sand column hydraulic conductivity have little differences (the powers of $P, D_{\mathrm{r}}, R_{\mathrm{s}}$, and $C_{\mathrm{u}}$ are $0.46,0.43,0.40$, and 0.56 , respectively), and the fitted power of $\mathrm{H}$ is -1.51 . The negative sign means that the pile distance has a negative influence on the hydraulic conductivity of the surrounding soil. As its absolute value is greater than the other variables, the pile distance has a relatively greater influence.

\section{Conclusions}

In this study, an innovative continuous hydraulic conductivity measurement system is developed to investigate the clogging mechanism of PCPs caused by sand piping. A series of laboratory simulation tests is conducted using this system to demonstrate the effects of pervious concrete porosity, grading of fine movable particles, mix ratio of skeleton particles to movable particles, relative density of soil, 
474 and distance between PCPs on the PCP clogging. The main conclusions are as follows:

475 1. The average hydraulic conductivity of soil after achieving stability is a comprehensive reflection 476 of two contradictory aspects: the dense filter zone near the soil-pervious concrete interface formed by 477 seepage, which decreases the hydraulic conductivity of soil, and the transport of soil particles from the 478 soil column, which increases the hydraulic conductivity of soil.

479 2. The variation in the electrical conductivity of pervious concrete closely follows its clogging 480 process. Therefore, the measurement of electrical conductivity, which is much more convenient, can 481 be used as an indicator of pervious concrete clogging.

482 3. In this study, PCP clogging rarely occurs in cases of small pervious concrete porosity, small 483 movable sand particle size, high sand relative density, and large pile distances.

484 Based on the test results, preliminary clogging models of pervious concrete and sand columns are 485 proposed. These models can approximately estimate the hydraulic conductivity of PCPs after clogging 486 occurs.

\section{Acknowledgments}

488

489

490

491

492

This work is supported by the Natural Science Foundations of China (Nos. 51778346, 51479105, and 51279094), the key research and development program of Shandong Province (2017GGX50102), the Fund of the Science, Technology and Innovation Commission of Shenzhen Municipality (JCYJ20160429183630760) and the Science Fund for Distinguished Young Scholars of Shandong Province (No. JQ201416). 


\section{References}

Adalier K, and Elgamal, A. 2004. Mitigation of liquefaction and associated ground deformations by stone columns. Engineering Geology, 72(3-4):275.

Ariyarathne, P., Liyanapathirana, D., and Leo, C. 2013. "Comparison of Different Two-Dimensional Idealizations for a Geosynthetic-Reinforced Pile-Supported Embankment.” Int. J. Geomech., v.13(6), p.754-768.

Basu, D., and Madhav, M.R. 2000. "Effect of Prefabricated Vertical Drain Clogging on the Rate of Consolidation: A Numerical Study.” Geosynth. Int., v.7(3), p.189-215.

Blazejeski, R., and Sadzide, M. B. 1997. "Soil clogging phenomena in constructed wetlands with surface flow." Water Sci. Technol., v.35(5), p.183-188.

Boulanger, R.W., Idriss, I.M., Stewart, D.P., Hashash, Y.M.A., and Schmidt, B. 1998 "Drainage Capacity of Stone Columns or Gravel Drains for Mitigating Liquefaction Hazards," Geotech. Earthquake Engrg. and Soil Dynamics Conf. III, ASCE, Vol I, pp. 678-690, Seattle, Washington.

Cui, X. Z., Zhang, J., Zhang, N., Gao, Z. J., Sui, W., and Wang, C. 2015. "Improvement of Permeability Measurement Precision of Pervious Concrete.” J. Test. Eval., v.43(4), p.812-819.

Deo, O., Sumanasooriya, M., and Neithalath, N. 2010. "Permeability Reduction in Pervious Concretes due to Clogging: Experiments and Modeling.” J. Mater. Civ. Eng., v.22(7), p.741-751.

Ferreira Pinto, A.P., and Delgado Rodrigues, J. 2008. "Stone consolidation, the role of treatment procedures Original Research Article.” J. Cultural Heritage, v.9(1), p.38-53.

Ghidaglia C., De Arcangelis L., Hinch J., and Guazzelli, E. 1996. "Transition in particle capture in deep bed filtration.” Phys. Rev., v.53(4), p.3028-3031.

Guetif, Z., Bouassida, M., and Debats, J.M. 2007. "Improved soft clay characteristics due to stone 
column installation.” Comput. Geotech., v.34, p.104-111.

Haselbach, L. 2010. "Potential for Clay Clogging of Pervious Concrete under Extreme Conditions." J. Hydrol. Eng., v.15(1), p.67-69.

Haselbach, L., Valavala, S., and Montes, F. 2006, "Permeability predictions for sand clogged portland cement pervious concrete pavement systems." J. Environ. Manage., v.81(1), p.42-49.

Haldar, S., and Babu, G. 2010. "Failure Mechanisms of Pile Foundations in Liquefiable Soil: Parametric Study.” Int. J. Geomech., v.10(2), p.74-84.

Hughes, J. M.O., and Withers, N.J. 1974. "Reinforcing of soft cohesive soils with stone columns." Ground Eng., v.7(3), p.42-49.

Jia, J.Q., Wang, H.T., Li, J., Zhang X., and Fan, X.G. 2011. “Analysis of bearing capability of CFG pile composite foundation.” J. Chongqing Univ., v.34(9), p.117-127. [in Chinese].

Jimenez, F.E.P., and Perez, M.A.C. 1990. "Analysis and evaluation of the performance of porous asphalt: the Spanish experience.” In: Meyer, W.E., Reichert, J. (Eds.), Surface Characteristics of Roadway: International Research and Technologies, ASTM STP 1031. American Society for Testing and Materials, PA, p.512-527.

Kayhanian, M., Anderson, D., Harvey, J.T., Jones, D., and Muhunthan, B. 2012. "Permeability measurement and scan imaging to assess clogging of pervious concrete pavements in parking lots." J. Environ. Manage., v.95, p.114-123.

Lafleur, J. 1984. Filter testing of broadly graded cohesionless tills. Canadian Geotechnical Journal, 21: 634-643.

Lee, J.S., and Pande, G.N. 1998. “Analysis of stone-column reinforced foundations.” Inter. J. Numer. Anal. Methods Geomech., v.22(12), p.1001-1020. 
Le Hello, B., and Villard, P. 2009. "Embankments reinforced by piles and geosynthetics-numerical and experimental studies with the transfer of load on the soil embankment." Eng. Geology, v.106, p.78-91.

Li, K.W., Shapiro M., Horne, R.N., Ma, S.X., Hajari, A., and Mudhhi, M. 2014. "In situ estimation of relative permeability from resistivity measurements.” Petrol. Geosci., v. 20, p.143-151.

Lin, H., Suleiman, M.T., Jabbour, H., Brown, D., and Kavazanjian, E. 2016. "Enhancing the Axial Compression Response of Pervious Concrete Ground Improvement Piles Using Bio-Grouting.” Journal of Geotechnical and Geoenvironmental Engineering, 142(10): 04016045.

Liu, J. 2006. "Seepage control of earth-rock dams theoretical basis, engineering experiences and lessons.” Beijing: China Water \& Power Press. (in Chinese)

Luck, J.D., Workman, S.R., Higgins, S.F., and Coyne, M.S. 2006. "Hydrologic properties of pervious concrete." Trans. ASAE, v.49, p.1807-1813.

Montes, F., Valavala, S., and Haselbach, L. 2005. "A new test method for porosity measurements of portland cement pervious concrete.” J. ASTM Int., v.2(1), p.13.

Narayan, R., Coury, J.R., Masliyah, J.H., and Gray, M.R. 1997. "Particle trapping and plugging in packed-bed reactors". Ind. Eng. Chem. Res., v.36, p.4620-4627.

Neithalath, N., Weiss, J., and Olek, J. 2006. “Characterizing enhanced porosity concrete using electrical impedance to predict acoustic and hydraulic performance." Cement Concrete Comp., v.36(11), p.2074-2085.

Ni, L., Suleiman, M.T., and Raich, A. 2016. "Behavior and Soil-Structure Interaction of Pervious Concrete Ground Improvement Piles under Lateral Loading.” Journal of Geotechnical and Geoenvironmental Engineering, 142(2): 04015071. 
Poorooshasb, H.B., and Meyerhof G.G. 1997. "Analysis of behaviour of stone columns and lime columns." Comput. Geotech., 20(1), 47-70.

Reddi, L.N., Xiao, M., Hajra, M.G., and Lee, I. M. 2000. "Permeability reduction of soil filters due to physical clogging." J. Geotech. Geoenviron. Eng., v.126(3), p.236-246.

Reddi, L.N., Xiao, M., Hajra, M.G., and Lee, I. M. 2005. "Physical clogging of soil filters under constant flow rate versus constant head." Can. Geotech. J., v.42, p.804-811.

Rollin, A., and Lombard, G. 1988. "Mechanisms affecting long-term filtration behavior of geotextiles." Geotext. Geomembranes, v.7(1-2), p.119-145.

Samouëlian, A., Cousin, I., Tabbagh, A., Bruand, A., and Richard, G. 2005. "Electrical resistivity survey in soil science: a review.” Soil Till. Res., v.83(2), p.173-193.

Sariosseiri, F., and Muhunthan, B. 2009. "Effect of cement treatment on geotechnical properties of some Washington State soils.” Eng. Geol., v.104, p.119-125.

Schlüter, W., and Jefferies, C. 2002. "Modeling the outflow from a porous pavement." Urban Water, v.4(3), p.245-253.

Shen, S.L., Cui, Q.L., Ho, C.E., and Xu, Y.S. 2016. "Ground Response to Multiple Parallel Microtunneling Operations in Cemented Silty Clay and Sand.” J. Geotech. Geoenviron. Eng., 142(5): 04016001.

Shen, S. L., Wang, Z. F., and Cheng, W.C. 2017. "Estimation of lateral displacement induced by jet grouting in clayey soils." Géotechnique, 67(7): 621-630.

Shen, S.L., Wang, Z.F., Yang, J., and Ho, C.E. 2013. "Generalized Approach for Prediction of Jet Grout Column Diameter.” J. Geotech. Geoenviron. Eng., 139: 2060-2069.

Shen, S.L., and Xu, Y.S. 2011. "Numerical evaluation of land subsidence induced by groundwater 
pumping in Shanghai." Can. Geotech. J. 48: 1378-1392.

Suleiman, M.T., Ni, L., and Raich, A. 2014. "Development of Pervious Concrete Pile Ground-Improvement Alternative and Behavior under Vertical Loading." Journal of Geotechnical and Geoenvironmental Engineering, 140(7): 04014035.

Suleiman, M.T., Raich, A., and O’Loughlin, M. 2011. “Pervious Concrete Piles, An Innovative Ground Improvement Alternative.” Proceedings of 2011 NSF Engineering Research and Innovation Conference, Atlanta, Georgia.

Tan, S.A., Fwa, T.F., and Han, C. T. 2003. "Clogging evaluation of permeable bases. ” J. Transp. Eng., v.129(3), p.309-315.

Tennis, P. D., Leming, M. L., and Akers, D. J. 2004. Pervious Concrete Pavements, EB302, Portland Cement Association, Skokie, Illinois, and National Ready Mixed Concrete Association, Silver Spring, Maryland.

Terzaghi, K. 1929. "Effect of minor geologic details on the safety of dams." Am. Inst. Min. Met. Eng. Tech. Publ., v.215, p.31-44.

Tomlinson S. S., and Vaid, Y.P. 2000. Seepage forces and confining pressure effects on piping erosion. Canadian Geotechnical Journal, 2000, 37 (1), 1-13.

Turesson, A. 2006. "Water content and porosity estimated from ground-penetrating radar and resistivity." J. Appl. Geophys., v.58(2), p.99-111.

Wu, F.-C., and Huang, H.T. 2000. "Hydraulic resistance induced by deposition of sediment in porous medium.” J. Hydraul. Eng., v.126(7), p.547-551.

Zhang, D., Cao, Z., Fan, L., Liu, S., and Liu, W. 2014. "Evaluation of the influence of salt concentration on cement stabilized clay by electrical resistivity measurement method." Eng. 
Geology, v.170(20), p.80-88.

Zhang, J., Cui, X.Z., Huang, D., Jin, Q., Lou, J.J., and Tang, W.Z. 2016. "Numerical simulation of consolidation settlement of pervious concrete pile composite foundation under road embankment.” Int. J. Geomech., v. 16(1), B4015006.

Zheng, J.J., Abusharar, S.W., and Wang, X.Z. 2008. "Three-dimensional nonlinear finite element modeling of composite foundation formed by CFG-lime piles." Comp. Geotech., v.35, p.637-643.

Zou Y., Boley, C., and Wehr, W. 2010. On stress state dependent contact erosion during the constructing of stone columns. International conference on scour and erosion, San Francisco, 241-250. 


\section{List of figure captions}

Fig. 1 Schematic of PCP clogging caused by soil piping

Fig. 2 Micro bridge network formation (Rollin and Lombard 1988)

Fig. 3 Schematic of test system for PCP clogging caused by soil piping

Fig. 4 Sketch of experimental setup design principle

Fig. 5 Influence of pervious concrete porosity on clogging: (a) NP time history curves of sand; (b)

NP time history curves of pervious concrete; (c) NEC time history curves of pervious concrete

Fig. 6 Influence of movable particle size on clogging: (a) NP time history curves of sand; (b) NP time history curves of pervious concrete

Fig. 7 Clogging mechanisms of sands with different movable particles: (a) Well-graded sand; (b) Single-size sand

Fig. 8 Influence of sand mixing proportion on clogging: (a) NP time history curves of sand; (b) NP time history curves of pervious concrete

Fig. 9 Proportions of movable particles for each layer after testing

Fig. 10 Influence of relative density of sand on clogging: (a) NP time history curves of sand; (b) NP time history curves of pervious concrete

Fig. 11 Influence of sand column height on clogging: (a) NP time history curves of sand; (b) NP time history curves of pervious concrete

Fig. 12 Relationship between tested coefficient $\alpha$ and fitted coefficient $\alpha$

Fig. 13 Relationship between tested and fitted $k_{\mathrm{s}} / \boldsymbol{k}_{\mathrm{s} 0}$ 


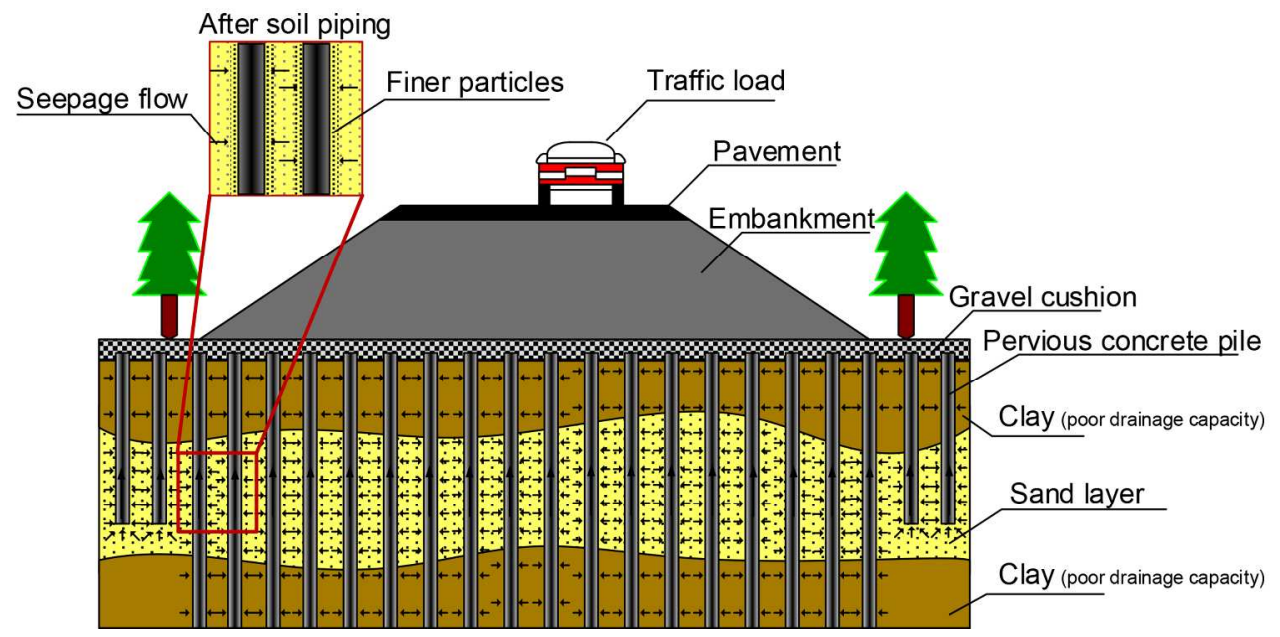

Fig. 1. Schematic of PCP clogging caused by soil piping $194 \times 92 \mathrm{~mm}(300 \times 300 \mathrm{DPI})$ 


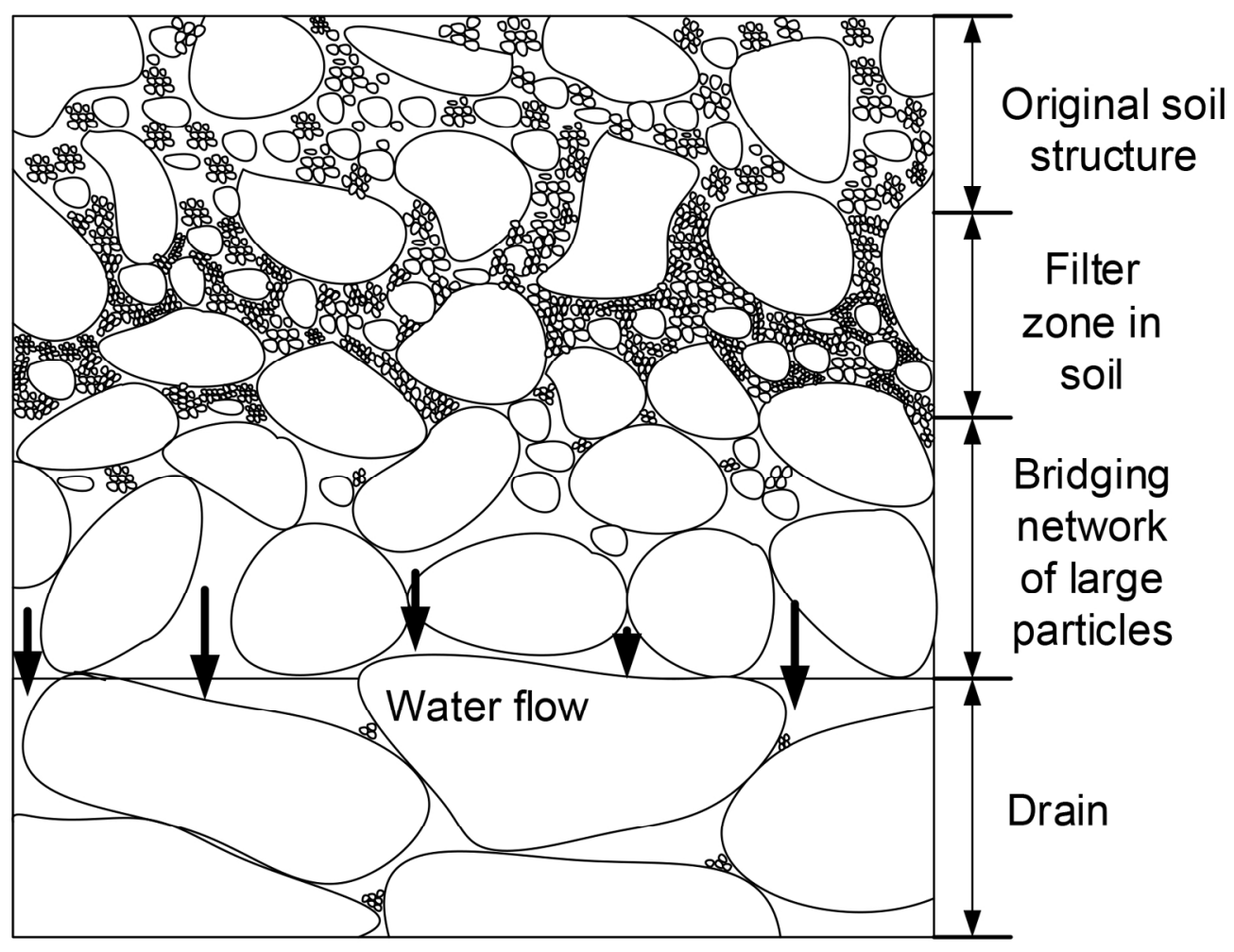

Fig. 2 Micro bridge network formation (Rollin and Lombard, 1988)

$160 \times 121 \mathrm{~mm}(300 \times 300 \mathrm{DPI})$ 


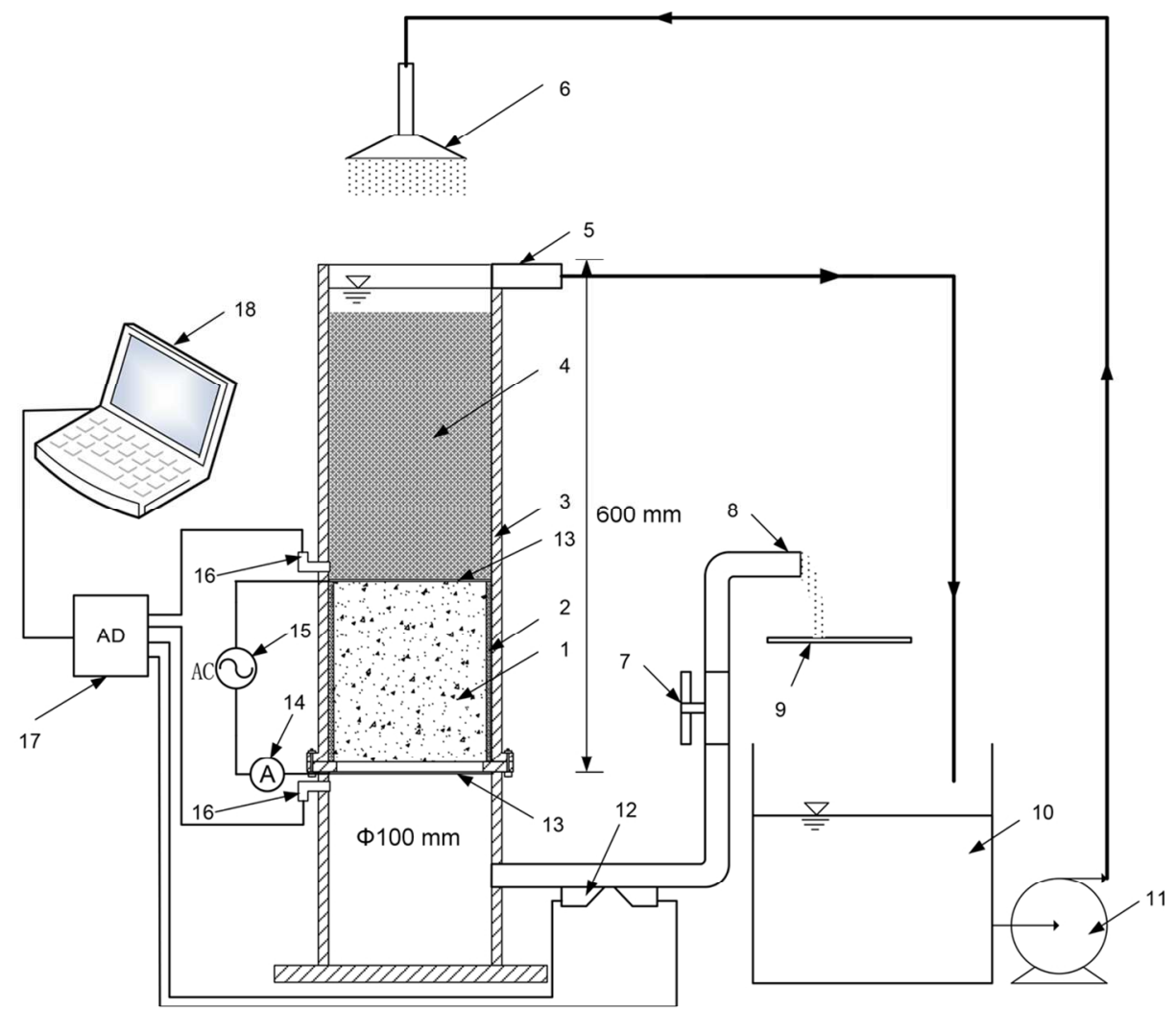

1. Pervious concrete sample; 2. Petroleum jelly and rubber cushion; 3. Plexiglass sleeve; 4. sand; 5. Overflow (height adjustable); 6. Sprinkler; 7. Valve; 8. Outflow; 9. Filter; 10. Water container; 11. Pump; 12. ultrasonic wave flow meter; 13. wire netting; 14. Current meter; 15. alternate current power source; 16. Pressure sensor; 17. Data acquisition system; 18. PC.

Fig. 3 Schematic of test system for PCP clogging of PCP caused by soil piping $473 \times 423 \mathrm{~mm}(72 \times 72 \mathrm{DPI})$ 


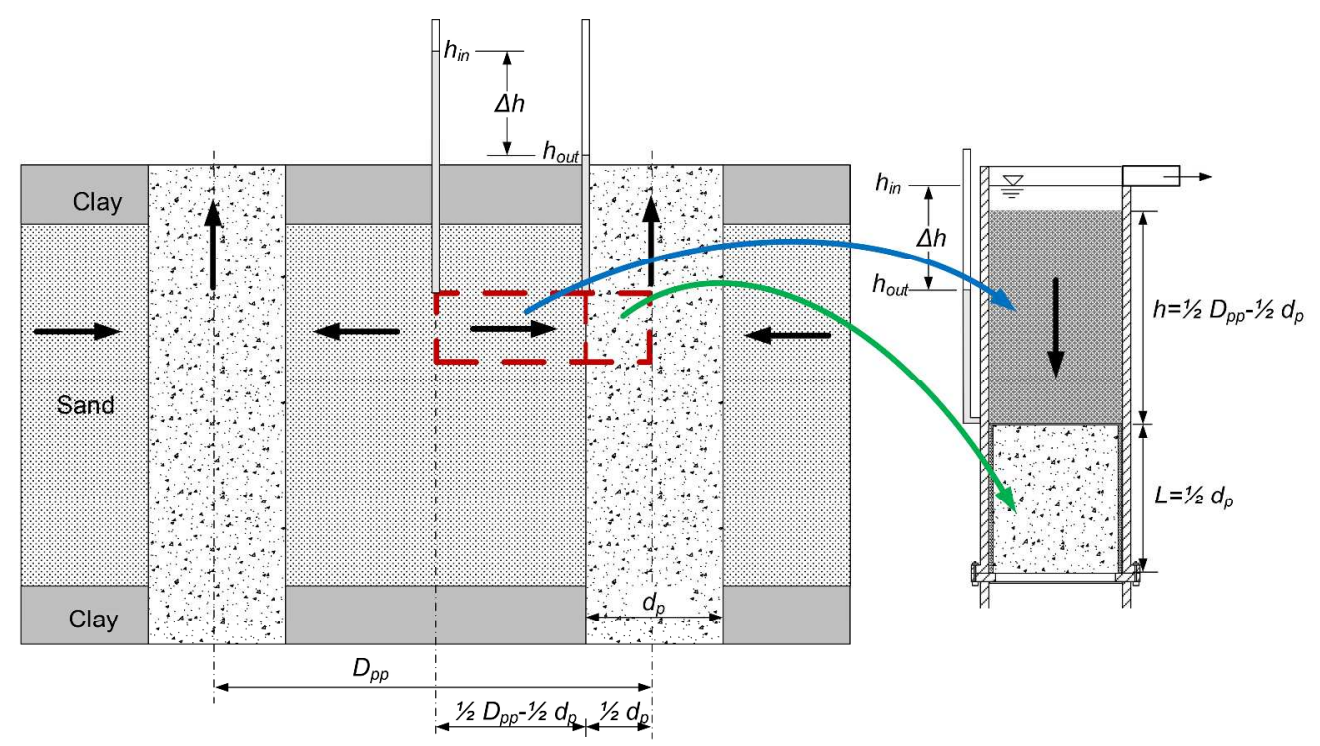

Fig. 4 Sketch of experimental setup design principle $332 \times 184 \mathrm{~mm}(300 \times 300$ DPI $)$ 

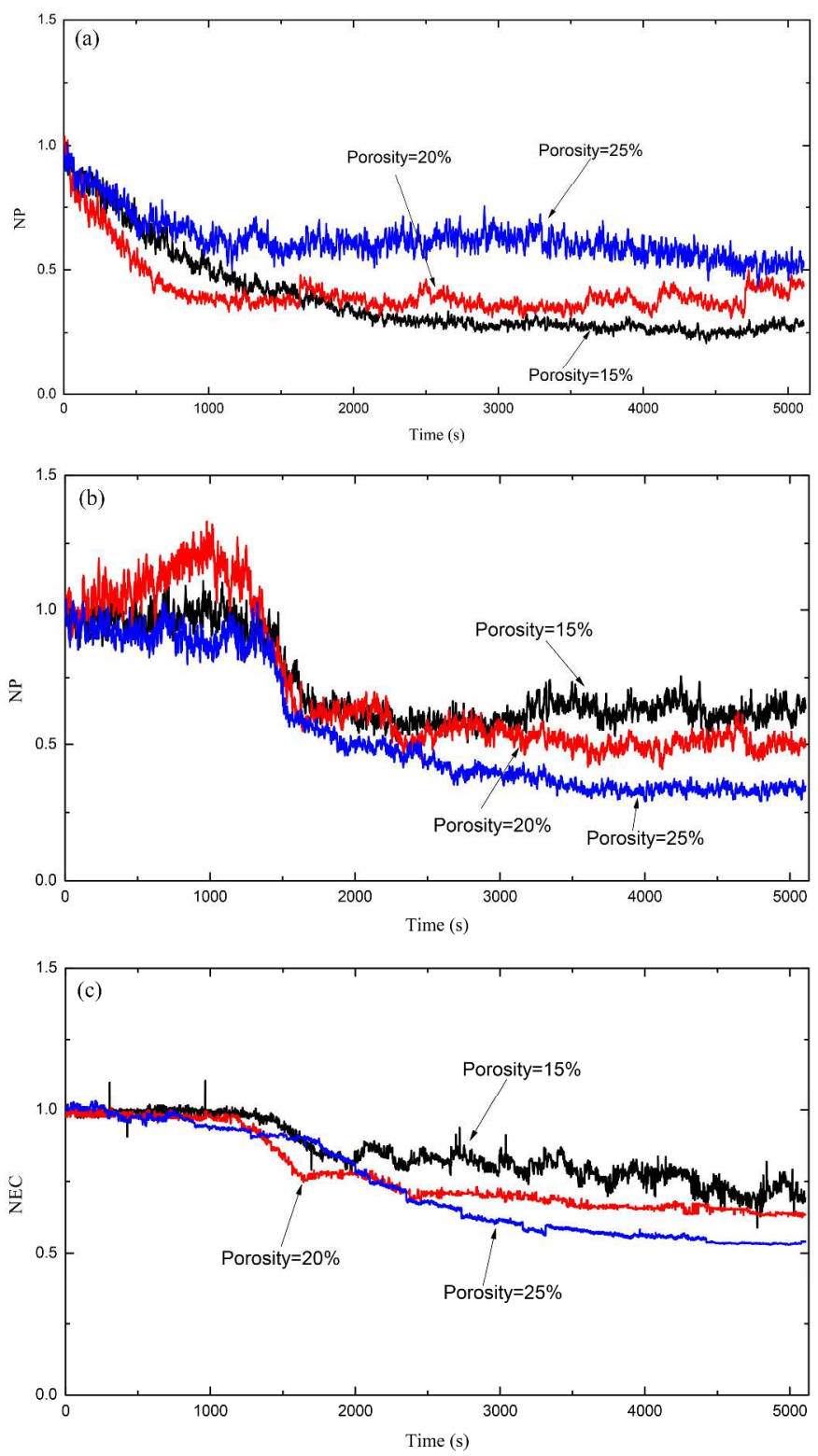

Fig. 5 Influence of pervious concrete porosity on clogging: (a) NP time history curves of sand; (b) NP time history curves of pervious concrete; (c) NEC time history curves of pervious concrete

$303 \times 543 \mathrm{~mm}(300 \times 300$ DPI $)$ 

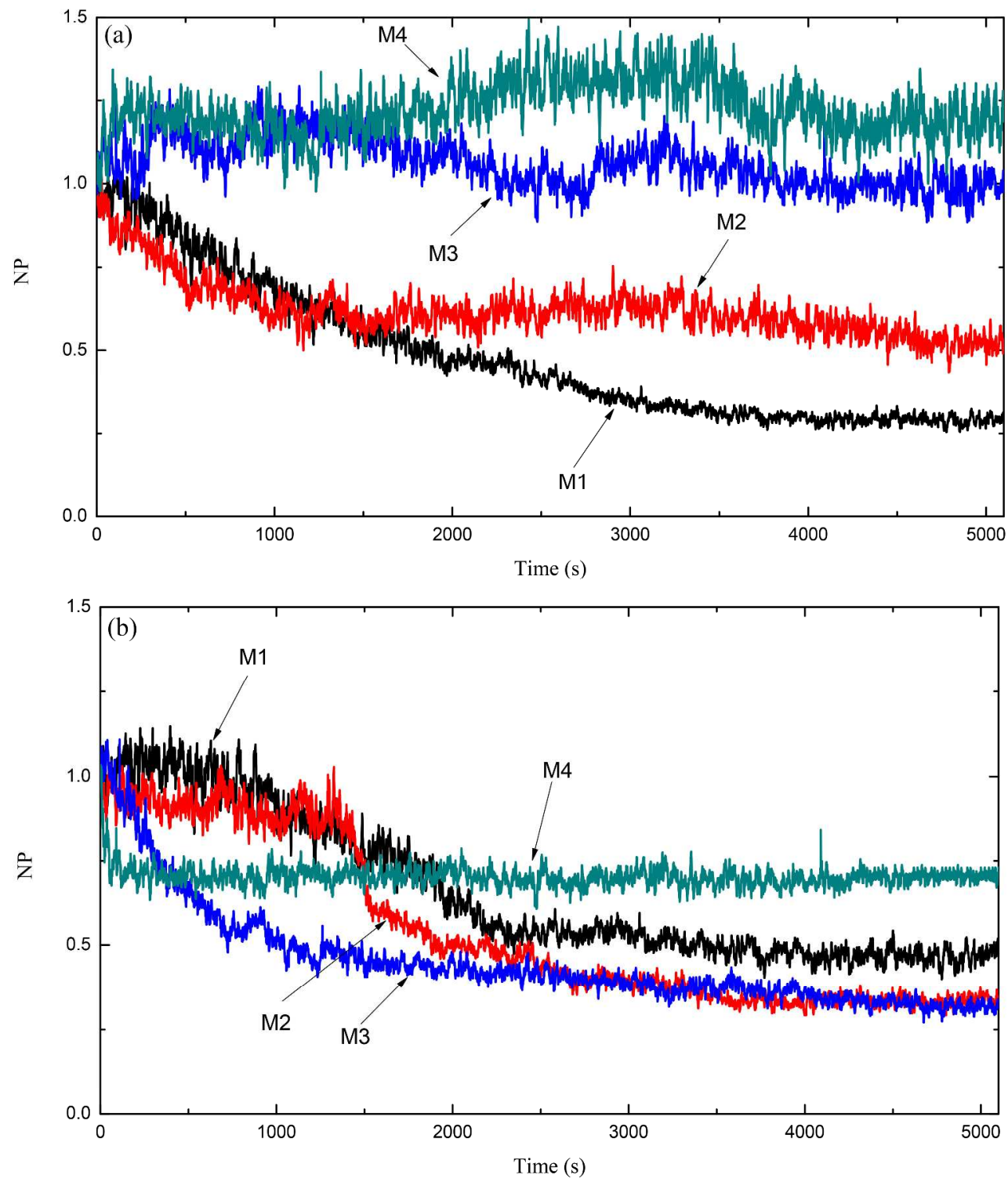

Fig. 6 Influence of movable particle size on clogging: (a) NP time history curves of sand; (b) NP time history curves of pervious concrete

$331 \times 397 \mathrm{~mm}(300 \times 300 \mathrm{DPI})$ 


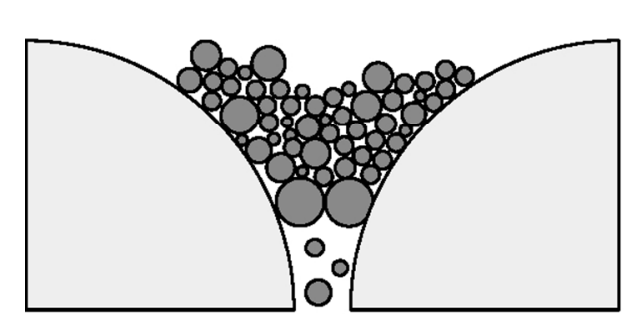

(a) Well-graded sand

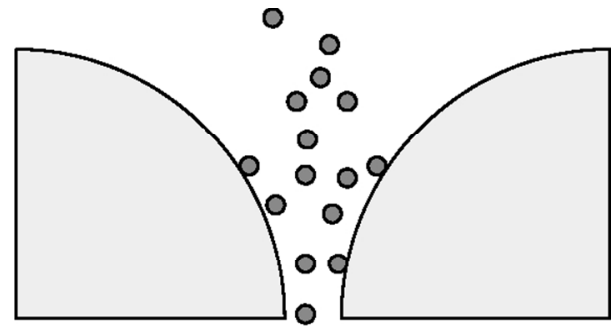

(b) Single size sand

Fig. 7 Clogging mechanisms of sands with different movable particles ( $a$, Well-graded sand; $b$, Single size sand)

$157 \times 46 \mathrm{~mm}(200 \times 200$ DPI $)$ 

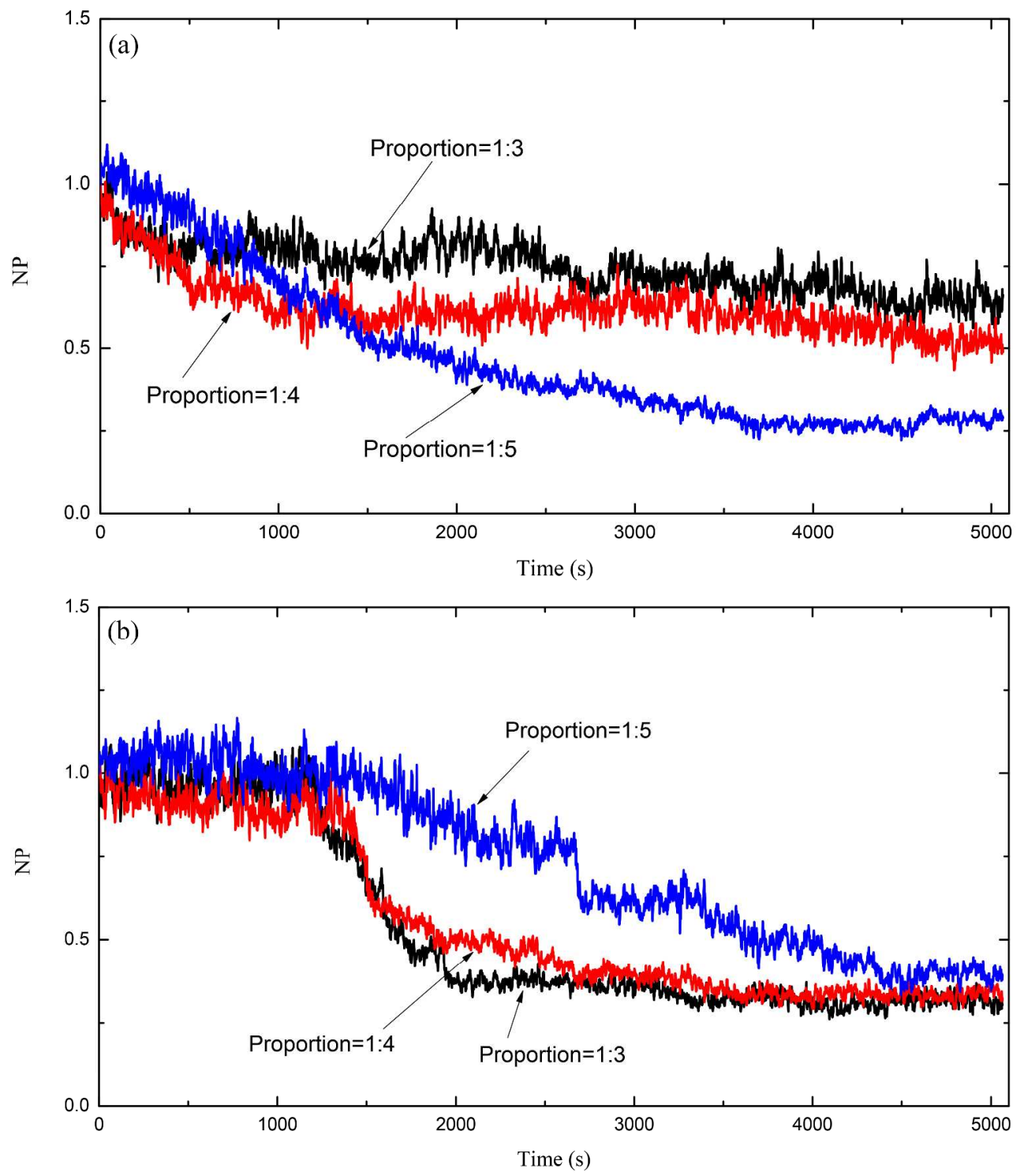

Fig. 8 Influence of sand mixing proportion on clogging: (a) NP time history curves of sand; (b) NP time history curves of pervious concrete

$$
313 \times 363 \mathrm{~mm}(300 \times 300 \mathrm{DPI})
$$




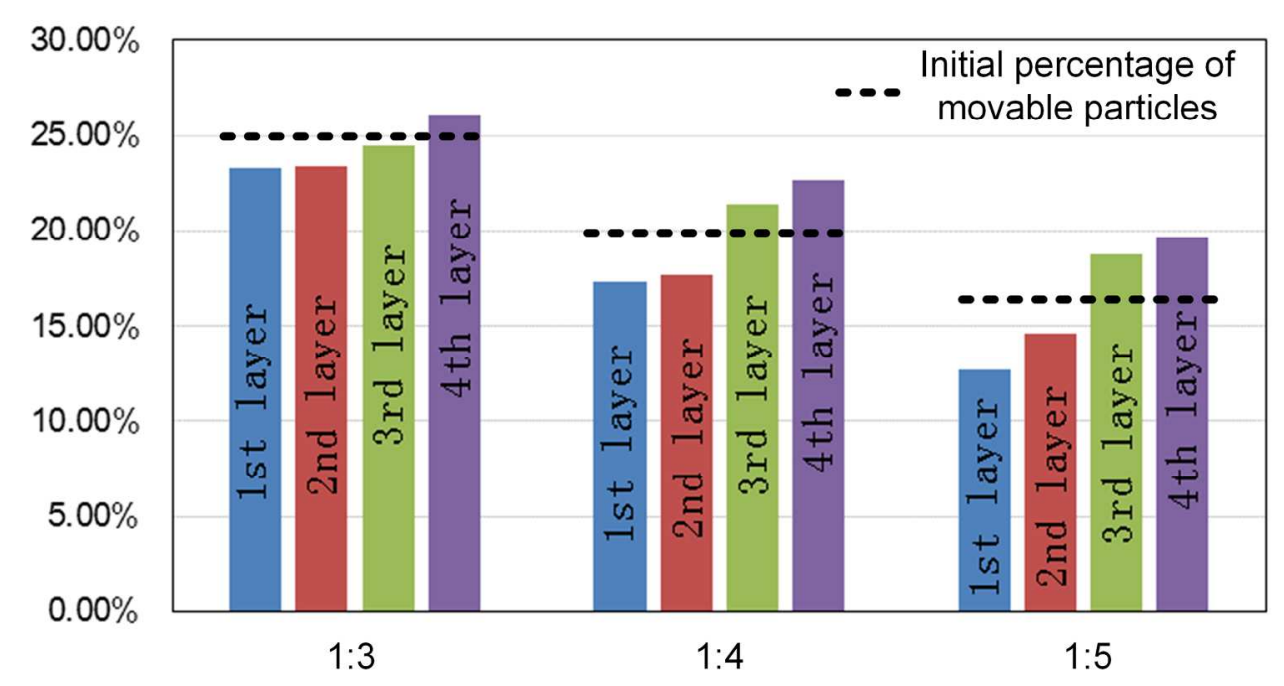

Fig. 9 The proportions of movable particles for each layer after testing $769 \times 423 \mathrm{~mm}(72 \times 72 \mathrm{DPI})$ 

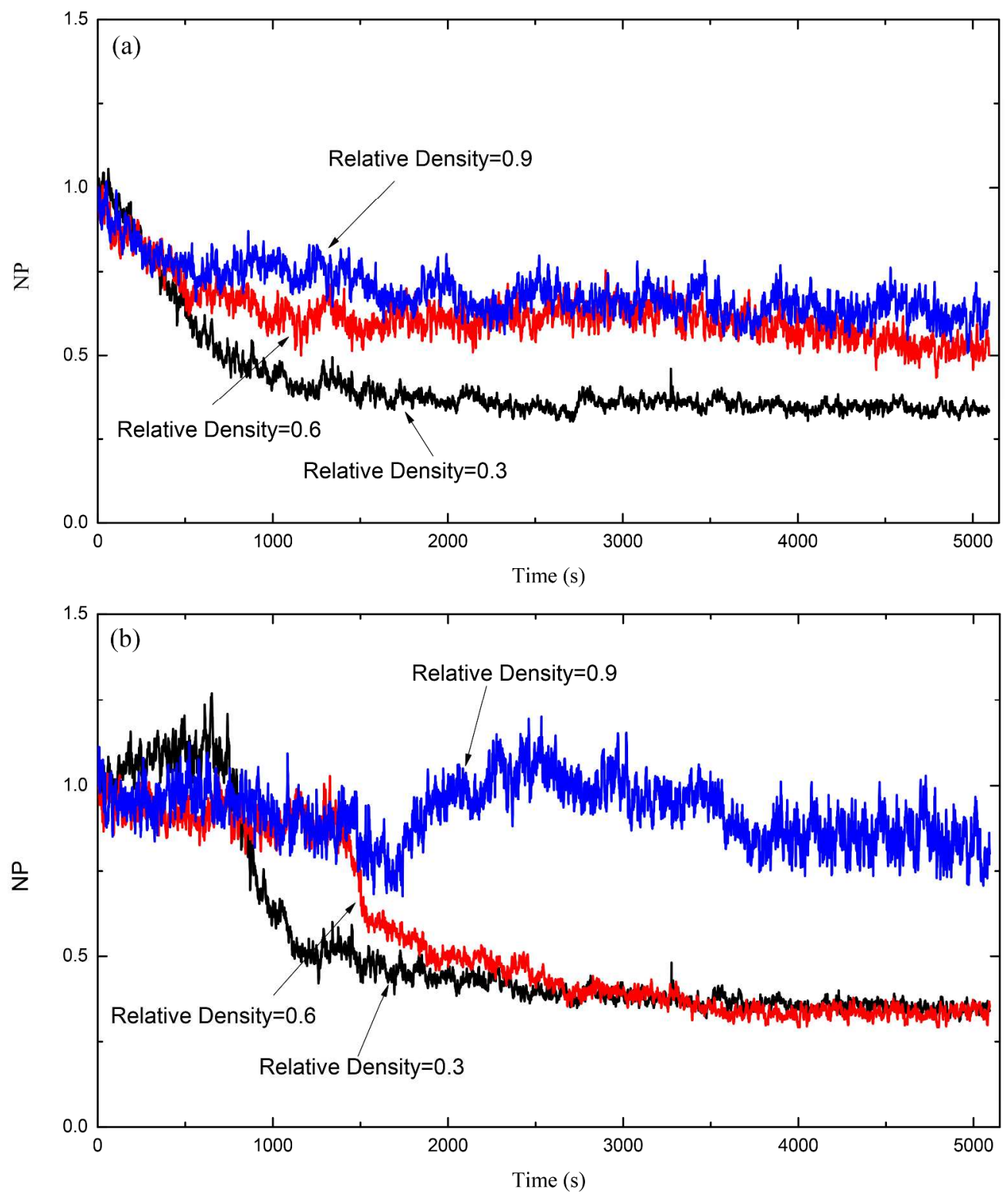

Fig. 10 Influence of relative density of sand on clogging: (a) NP time history curves of sand; (b) NP time history curves of pervious concrete

$321 \times 384 \mathrm{~mm}(300 \times 300 \mathrm{DPI})$ 

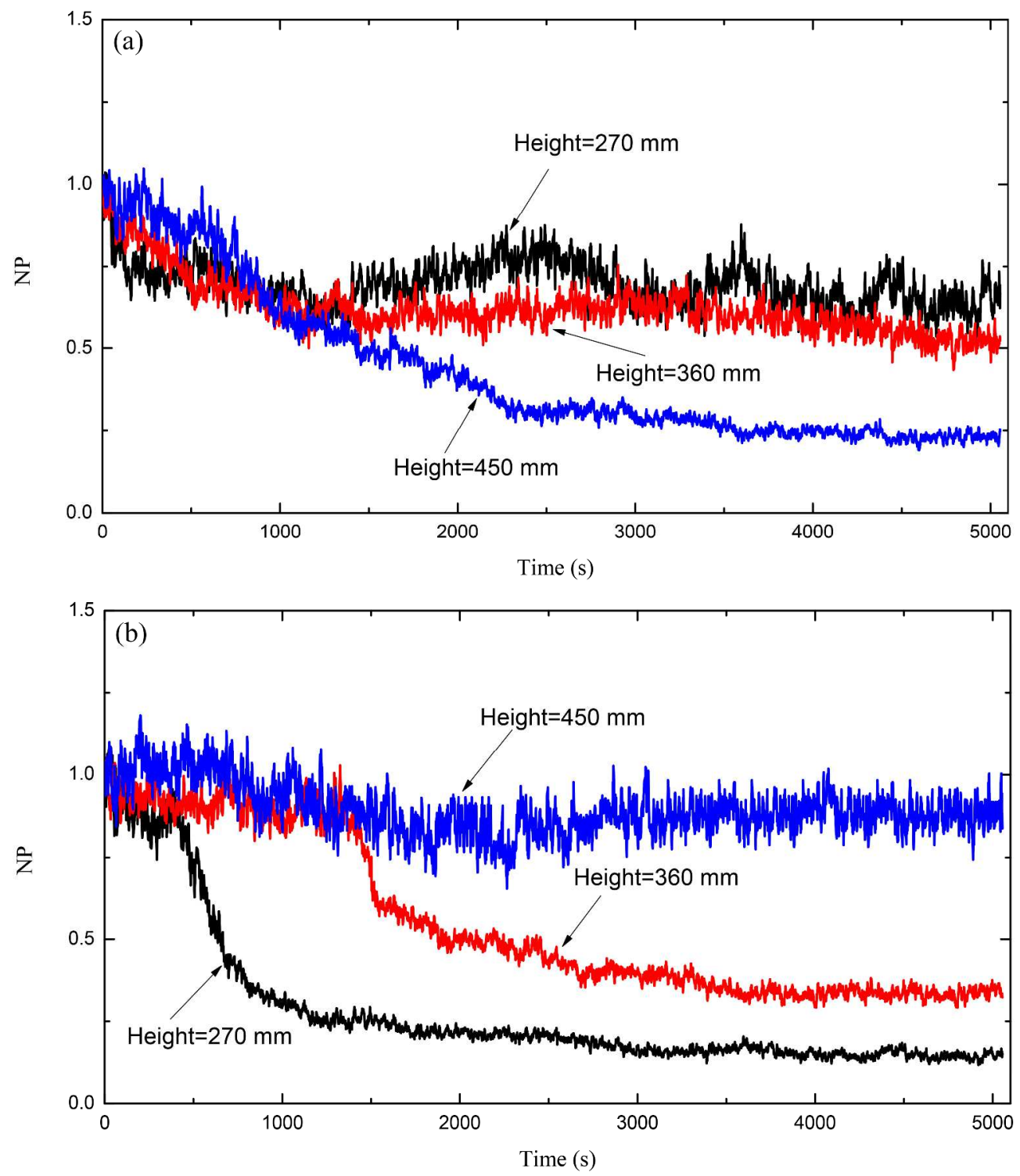

Fig. 11 Influence of sand column height on clogging: (a) NP time history curves of sand; (b) NP time history curves of pervious concrete

$311 \times 361 \mathrm{~mm}(300 \times 300 \mathrm{DPI})$ 


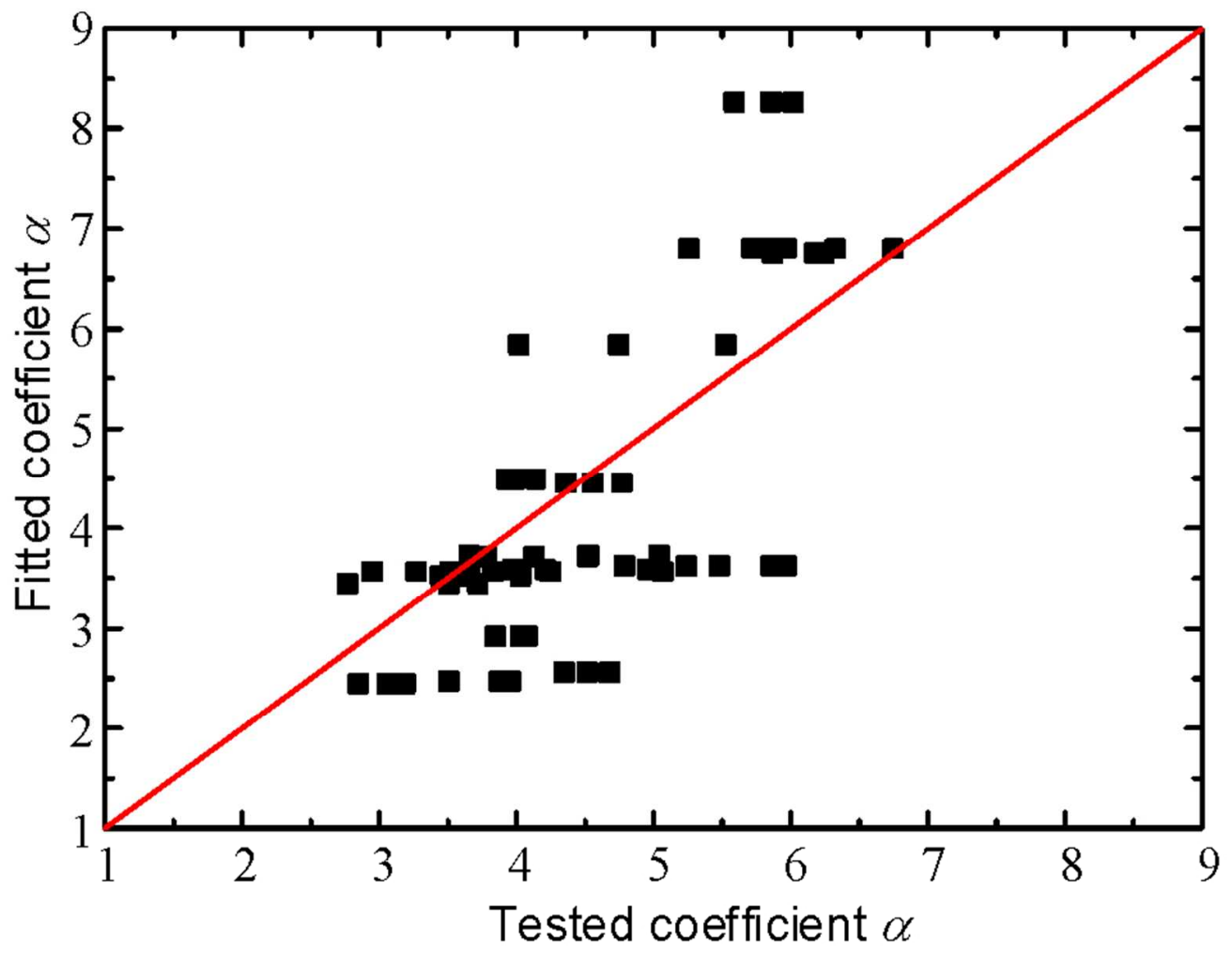

Fig. 12 Relationship between tested coefficient $a$ and fitted coefficient a $80 \times 62 \mathrm{~mm}(300 \times 300 \mathrm{DPI})$ 


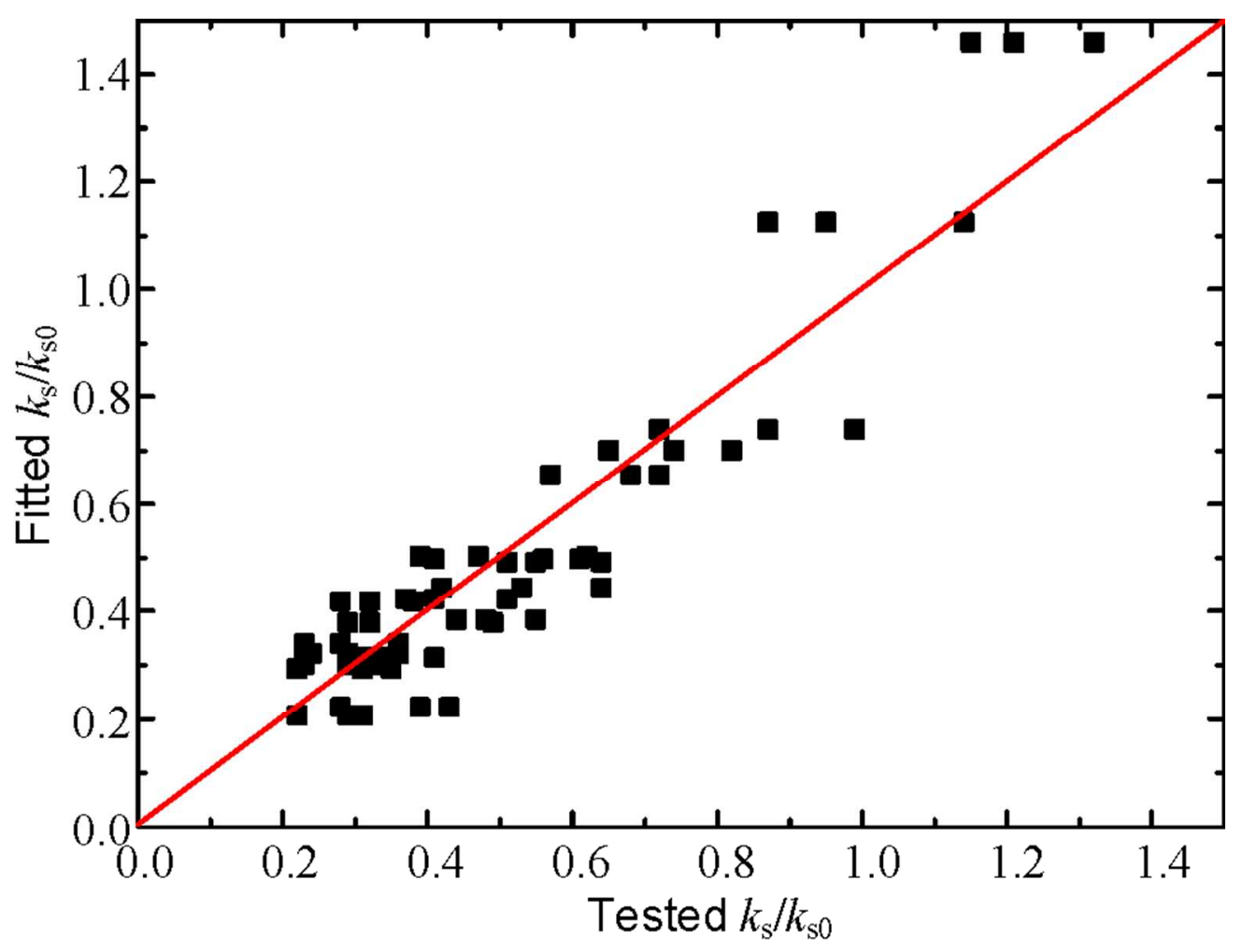

Fig. 13 Relationship between tested and fitted ks/ks0

$83 \times 63 \mathrm{~mm}(300 \times 300 \mathrm{DPI})$ 
Table 1 Physical indexes of coarse aggregate

\begin{tabular}{ccccc}
\hline Particle size & Apparent density & Stacking density & Porosity & Crushed value \\
$(\mathrm{mm})$ & $\left(\mathrm{g} / \mathrm{cm}^{3}\right)$ & $\left(\mathrm{g} / \mathrm{cm}^{3}\right)$ & $(\%)$ & $(\%)$ \\
\hline $4.75 \sim 9.5$ & 2.665 & 1.655 & 37.89 & 8.6 \\
\hline
\end{tabular}


Table 2 Mix proportions per cubic meter of pervious concrete

\begin{tabular}{ccccc}
\hline $\begin{array}{c}\text { Target porosity } \\
(\%)\end{array}$ & Cement & Water & Aggregate & Superplasticizer \\
\hline 15 & 335 & 121 & & dosage $(\%)$ \\
20 & 262 & 94 & 1622 & 0.8 \\
25 & 189 & 68 & & \\
\hline
\end{tabular}


Table 3 Characteristics of particles used in the tests

\begin{tabular}{|c|c|c|c|c|c|c|c|}
\hline \multirow{2}{*}{ Particle type } & \multirow{2}{*}{ Particle name } & \multicolumn{6}{|c|}{ Mass percentage (\%) } \\
\hline & & $4.75-9.5 \mathrm{~mm}$ & $2.36-4.75 \mathrm{~mm}$ & $1.18-2.36 \mathrm{~mm}$ & $0.6-1.18 \mathrm{~mm}$ & $0.3-0.6 \mathrm{~mm}$ & $0.15-0.3 \mathrm{~mm}$ \\
\hline & M1 & 0 & 11.6 & 28 & 35 & 4.5 & 20.9 \\
\hline Movable & M2 & 0 & 0 & 0 & 97.4 & 2.6 & 0 \\
\hline \multirow[t]{2}{*}{ particle } & M3 & 0 & 0 & 0 & 17.2 & 78.2 & 4.6 \\
\hline & M4 & 0 & 0 & 0 & 0 & 0 & 100 \\
\hline \multicolumn{8}{|l|}{ Skeleton } \\
\hline & $S$ & 100 & 0 & 0 & 0 & 0 & 0 \\
\hline particle & & & & & & & \\
\hline
\end{tabular}


Table 4 Different types of sand column mixtures

\begin{tabular}{cccccc}
\hline Name of & Movable & skeleton & Mass ratio of & Minimum & Maximum dry \\
mixture & particle & particle & movable and & dry density & density $(\mathrm{g} / \mathrm{ml})$ \\
& included & included & skeleton particle & $(\mathrm{g} / \mathrm{ml})$ & \\
M1-S-14 & M1 & $\mathrm{S}$ & $1: 4$ & 1.40 & 1.79 \\
M2-S-13 & M2 & $\mathrm{S}$ & $1: 3$ & 1.39 & 1.80 \\
M2-S-14 & M2 & $\mathrm{S}$ & $1: 4$ & 1.38 & 1.79 \\
M2-S-15 & M2 & $\mathrm{S}$ & $1: 5$ & 1.35 & 1.77 \\
M3-S-14 & M3 & $\mathrm{S}$ & $1: 4$ & 1.49 & 1.89 \\
M4-S-14 & M4 & $\mathrm{S}$ & $1: 4$ & 1.59 & 1.97 \\
\hline
\end{tabular}


Table 5 Test cases

\begin{tabular}{|c|c|c|c|c|c|}
\hline Cases & $\begin{array}{c}\text { Porosity of } \\
\text { pervious concrete } \\
\text { (\%) }\end{array}$ & $\begin{array}{c}\text { Name of } \\
\text { sand mixture }\end{array}$ & $\begin{array}{c}\text { Relative } \\
\text { density } \\
\mathrm{D}_{\mathrm{r}}\end{array}$ & $\begin{array}{l}\text { Height of sand } \\
\text { column (mm) }\end{array}$ & $\begin{array}{l}\text { Initial hydraulic } \\
\text { conductivity of } \\
\text { sand column } \\
(\mathrm{m} / \mathrm{s})\end{array}$ \\
\hline 1 & 15 & M2-S-14 & 0.6 & 360 & 0.019 \\
\hline 2 & 20 & M2-S-14 & 0.6 & 360 & 0.015 \\
\hline 3 & 25 & M2-S-14 & 0.6 & 360 & 0.013 \\
\hline 4 & 25 & M1-S-14 & 0.6 & 360 & 0.011 \\
\hline 5 & 25 & M3-S-14 & 0.6 & 360 & 0.019 \\
\hline 6 & 25 & M4-S-14 & 0.6 & 360 & 0.064 \\
\hline 7 & 25 & M2-S-13 & 0.6 & 360 & 0.011 \\
\hline 8 & 25 & M2-S-15 & 0.6 & 360 & 0.023 \\
\hline 9 & 25 & M2-S-14 & 0.3 & 360 & 0.028 \\
\hline 10 & 25 & M2-S-14 & 0.9 & 360 & 0.010 \\
\hline 11 & 25 & M2-S-14 & 0.6 & 270 & 0.013 \\
\hline 12 & 25 & M2-S-14 & 0.6 & 450 & 0.015 \\
\hline 13 & 15 & M1-S-14 & 0.3 & 270 & 0.014 \\
\hline 14 & 15 & M3-S-14 & 0.9 & 450 & 0.013 \\
\hline 15 & 20 & M1-S-14 & 0.6 & 450 & 0.013 \\
\hline 16 & 20 & M2-S-14 & 0.9 & 270 & 0.010 \\
\hline 17 & 20 & M3-S-14 & 0.3 & 360 & 0.023 \\
\hline 18 & 25 & M1-S-14 & 0.9 & 360 & 0.009 \\
\hline 19 & 25 & M2-S-14 & 0.3 & 450 & 0.021 \\
\hline 20 & 25 & M3-S-14 & 0.6 & 270 & 0.018 \\
\hline
\end{tabular}


Table 6 Size distributions of sand in each layer of sand column after the test

\begin{tabular}{|c|c|c|c|c|c|c|}
\hline \multirow{3}{*}{ Case } & \multirow{3}{*}{$\begin{array}{l}\text { Layers } \\
\text { (from up } \\
\text { to bottom) }\end{array}$} & \multicolumn{5}{|c|}{ Mass percentage of sand in each layer } \\
\hline & & $\begin{array}{l}\text { Skeleton } \\
\text { particle }\end{array}$ & \multicolumn{4}{|c|}{ Movable particle } \\
\hline & & $4.75-9.5 \mathrm{~mm}$ & $1.18-4.75 \mathrm{~mm}$ & $0.6-1.18 \mathrm{~mm}$ & $0.3-0.6 \mathrm{~mm}$ & $<0.3 \mathrm{~mm}$ \\
\hline \multirow{4}{*}{1} & 1st layer & $80.55 \% \uparrow$ & - & $19.05 \% \downarrow$ & $0.40 \% \downarrow$ & - \\
\hline & 2nd layer & $80.17 \% \uparrow$ & - & $19.41 \% \downarrow$ & $0.42 \% \downarrow$ & - \\
\hline & 3rd layer & $79.82 \% \downarrow$ & - & $19.70 \% \uparrow$ & $0.48 \% \downarrow$ & - \\
\hline & 4th layer & $75.25 \% \downarrow$ & - & $20.18 \% \uparrow$ & $0.57 \% \uparrow$ & - \\
\hline \multirow{4}{*}{2} & 1st layer & $81.27 \% \uparrow$ & - & $18.40 \% \downarrow$ & $0.34 \% \downarrow$ & - \\
\hline & 2nd layer & $80.12 \% \uparrow$ & - & $19.43 \% \downarrow$ & $0.45 \% \downarrow$ & - \\
\hline & 3rd layer & $79.63 \% \downarrow$ & - & $19.89 \% \uparrow$ & $0.48 \% \downarrow$ & - \\
\hline & 4th layer & $78.11 \% \downarrow$ & - & $21.39 \% \uparrow$ & $0.50 \% \downarrow$ & - \\
\hline \multirow{4}{*}{3} & 1st layer & $82.69 \% \uparrow$ & - & $16.86 \% \downarrow$ & $0.44 \% \downarrow$ & - \\
\hline & 2nd layer & $82.35 \% \uparrow$ & - & $17.20 \% \downarrow$ & $0.46 \% \downarrow$ & - \\
\hline & 3rd layer & $78.58 \% \downarrow$ & - & $20.89 \% \uparrow$ & $0.53 \% \uparrow$ & - \\
\hline & 4th layer & $77.35 \% \downarrow$ & - & $21.99 \% \uparrow$ & $0.65 \% \uparrow$ & - \\
\hline
\end{tabular}

Note: arrows indicate the changes in the proportions compared with initial values before test. 
Table 7 Size distributions of sand in each layer of sand column after the test

\begin{tabular}{|c|c|c|c|c|c|c|c|}
\hline \multirow{3}{*}{ Case } & Layers & \multicolumn{6}{|c|}{ Mass percentage of sand in each layer } \\
\hline & (from up & Skeleton & \multicolumn{5}{|c|}{ Movable particle } \\
\hline & bottom) & $>4.75 \mathrm{~mm}$ & $2.36-4.75 \mathrm{~mm}$ & $1.18-2.36 \mathrm{~mm}$ & $0.6-1.18 \mathrm{~mm}$ & $0.3-0.6 \mathrm{~mm}$ & $0.15-0.3 \mathrm{~mm}$ \\
\hline \multirow{4}{*}{3} & 1st layer & $82.69 \% \uparrow$ & - & - & $16.86 \% \downarrow$ & $0.44 \% \downarrow$ & - \\
\hline & 2nd layer & $82.35 \% \uparrow$ & - & - & $17.20 \% \downarrow$ & $0.46 \% \downarrow$ & - \\
\hline & 3rd layer & $78.58 \% \downarrow$ & - & - & $20.89 \% \uparrow$ & $0.53 \% \uparrow$ & - \\
\hline & 4th layer & $77.35 \% \downarrow$ & - & - & $21.99 \% \uparrow$ & $0.65 \% \uparrow$ & - \\
\hline \multirow{4}{*}{4} & 1st layer & $82.18 \% \uparrow$ & $2.41 \% \uparrow$ & $5.73 \% \uparrow$ & $5.2 \% \downarrow$ & $0.71 \% \downarrow$ & $3.77 \% \downarrow$ \\
\hline & 2nd layer & $81.93 \% \uparrow$ & $2.31 \% \downarrow$ & $5.62 \% \uparrow$ & $5.74 \% \downarrow$ & $0.80 \% \downarrow$ & $3.69 \% \downarrow$ \\
\hline & 3rd layer & $78.48 \% \downarrow$ & $2.22 \% \downarrow$ & $5.45 \% \downarrow$ & $8.51 \% \uparrow$ & $0.89 \% \downarrow$ & $4.45 \% \uparrow$ \\
\hline & 4th layer & $78.07 \% \downarrow$ & $2.17 \% \downarrow$ & $4.74 \% \downarrow$ & $8.89 \% \uparrow$ & $1.22 \% \uparrow$ & $4.90 \% \uparrow$ \\
\hline \multirow{4}{*}{5} & 1st layer & $85.23 \% \uparrow$ & - & - & $3.50 \% \uparrow$ & $10.57 \% \downarrow$ & $0.70 \% \downarrow$ \\
\hline & 2nd layer & $83.79 \% \uparrow$ & - & - & $2.48 \% \downarrow$ & $12.94 \% \downarrow$ & $0.80 \% \downarrow$ \\
\hline & 3rd layer & $83.07 \% \uparrow$ & - & - & $3.41 \% \downarrow$ & $12.69 \% \downarrow$ & $0.83 \% \downarrow$ \\
\hline & 4th layer & $80.02 \% \uparrow$ & - & - & $3.31 \% \downarrow$ & $15.68 \% \uparrow$ & $0.99 \% \uparrow$ \\
\hline \multirow{4}{*}{6} & 1st layer & $98.65 \% \uparrow$ & - & - & - & - & $1.35 \% \downarrow$ \\
\hline & 2nd layer & $87.86 \% \uparrow$ & - & - & - & - & $12.14 \% \downarrow$ \\
\hline & 3rd layer & $86.74 \% \uparrow$ & - & - & - & - & $13.26 \% \downarrow$ \\
\hline & 4th layer & $80.50 \% \uparrow$ & - & - & - & - & $19.50 \% \downarrow$ \\
\hline
\end{tabular}

Note: arrows indicate the changes in the proportions compared with initial values before test. 
Table 8 Size distributions of sand in each layer of sand column after the test

\begin{tabular}{|c|c|c|c|c|c|c|}
\hline \multirow{3}{*}{ Case } & \multirow{3}{*}{$\begin{array}{l}\text { Layers (from up } \\
\text { to bottom) }\end{array}$} & \multicolumn{5}{|c|}{ Mass percentage of sand in each layer } \\
\hline & & $\begin{array}{l}\text { Skeleton } \\
\text { particle }\end{array}$ & \multicolumn{4}{|c|}{ Movable particle } \\
\hline & & $>4.75 \mathrm{~mm}$ & $1.18-4.75 \mathrm{~mm}$ & $0.6-1.18 \mathrm{~mm}$ & $0.3-0.6 \mathrm{~mm}$ & $<0.3 \mathrm{~mm}$ \\
\hline \multirow{4}{*}{7} & 1st layer & $76.67 \% \uparrow$ & - & $22.82 \% \downarrow$ & $0.51 \% \downarrow$ & - \\
\hline & 2nd layer & $76.58 \% \uparrow$ & - & $22.88 \% \downarrow$ & $0.54 \% \downarrow$ & - \\
\hline & 3rd layer & $75.50 \% \uparrow$ & - & $23.87 \% \downarrow$ & $0.63 \% \downarrow$ & - \\
\hline & 4th layer & $73.86 \% \downarrow$ & - & $25.50 \% \uparrow$ & $0.64 \% \downarrow$ & - \\
\hline \multirow{4}{*}{3} & 1st layer & $82.69 \% \uparrow$ & - & $16.86 \% \downarrow$ & $0.44 \% \downarrow$ & - \\
\hline & 2nd layer & $82.35 \% \uparrow$ & - & $17.20 \% \downarrow$ & $0.46 \% \downarrow$ & - \\
\hline & 3rd layer & $78.58 \% \downarrow$ & - & $20.89 \% \uparrow$ & $0.53 \% \uparrow$ & - \\
\hline & 4th layer & $77.35 \% \downarrow$ & - & $21.99 \% \uparrow$ & $0.65 \% \uparrow$ & - \\
\hline \multirow{5}{*}{8} & 1st layer & $87.31 \% \uparrow$ & - & $12.35 \% \downarrow$ & $0.34 \% \downarrow$ & - \\
\hline & 2nd layer & $85.42 \% \uparrow$ & - & $14.19 \% \downarrow$ & $0.39 \% \downarrow$ & - \\
\hline & & & & & & \\
\hline & 3rd layer & $81.21 \% \downarrow$ & - & $18.27 \% \uparrow$ & $0.52 \% \uparrow$ & - \\
\hline & 4th layer & $80.32 \% \downarrow$ & - & $18.76 \% \uparrow$ & $0.92 \% \uparrow$ & - \\
\hline
\end{tabular}

Note: arrows indicate the changes in the proportions compared with initial values before test. 
Table 9 Size distributions of sand in each layer of sand column after the test

\begin{tabular}{|c|c|c|c|c|c|c|}
\hline \multirow{3}{*}{ Case } & Layers & \multicolumn{5}{|c|}{ Mass percentage of sand in each layer } \\
\hline & \multirow[t]{2}{*}{ (from up to } & Skeleton & \multicolumn{4}{|c|}{ Movable particle } \\
\hline & & $>4.75 \mathrm{~mm}$ & $1.18-4.75 \mathrm{~mm}$ & $0.6-1.18 \mathrm{~mm}$ & $0.3-0.6 \mathrm{~mm}$ & $<0.3 \mathrm{~mm}$ \\
\hline \multirow{4}{*}{9} & 1st layer & $85.03 \% \uparrow$ & - & $14.58 \% \downarrow$ & $0.39 \% \downarrow$ & - \\
\hline & 2nd layer & $80.46 \% \uparrow$ & - & $19.11 \% \downarrow$ & $0.43 \% \downarrow$ & - \\
\hline & 3rd layer & $78.52 \% \downarrow$ & - & $20.97 \% \uparrow$ & $0.51 \% \downarrow$ & - \\
\hline & 4th layer & $76.95 \% \downarrow$ & - & $22.41 \% \uparrow$ & $0.64 \% \uparrow$ & - \\
\hline \multirow{4}{*}{3} & 1st layer & $82.69 \% \uparrow$ & - & $16.86 \% \downarrow$ & $0.44 \% \downarrow$ & - \\
\hline & 2nd layer & $82.35 \% \uparrow$ & - & $17.20 \% \downarrow$ & $0.46 \% \downarrow$ & - \\
\hline & 3rd layer & $78.58 \% \downarrow$ & - & $20.89 \% \uparrow$ & $0.53 \% \uparrow$ & - \\
\hline & 4th layer & $77.35 \% \downarrow$ & - & $21.99 \% \uparrow$ & $0.65 \% \uparrow$ & - \\
\hline \multirow{4}{*}{10} & 1st layer & $82.18 \% \uparrow$ & - & $17.30 \% \downarrow$ & $0.52 \%$ & - \\
\hline & 2nd layer & $81.69 \% \uparrow$ & - & $17.98 \% \downarrow$ & $0.33 \% \downarrow$ & - \\
\hline & 3rd layer & $79.74 \% \downarrow$ & - & $19.84 \% \uparrow$ & $0.42 \% \downarrow$ & - \\
\hline & 4th layer & $79.00 \% \downarrow$ & - & $20.41 \% \uparrow$ & $0.59 \% \uparrow$ & - \\
\hline
\end{tabular}

Note: arrows indicate the changes in the proportions compared with initial values before test. 
Table 10 Size distributions of sand in each layer of sand column after the test

\begin{tabular}{|c|c|c|c|c|c|c|}
\hline \multirow{3}{*}{ Case } & \multirow{3}{*}{$\begin{array}{l}\text { Layers (from up } \\
\text { to bottom) }\end{array}$} & \multicolumn{5}{|c|}{ Mass percentage of sand in each layer } \\
\hline & & $\begin{array}{l}\text { Skeleton } \\
\text { particle }\end{array}$ & \multicolumn{4}{|c|}{ Movable particle } \\
\hline & & $>4.75 \mathrm{~mm}$ & $1.18-4.75 \mathrm{~mm}$ & $0.6-1.18 \mathrm{~mm}$ & $0.3-0.6 \mathrm{~mm}$ & $<0.3 \mathrm{~mm}$ \\
\hline \multirow{4}{*}{11} & 1st layer & $80.99 \% \uparrow$ & - & $18.63 \% \downarrow$ & $0.38 \% \downarrow$ & - \\
\hline & 2nd layer & $79.97 \% \downarrow$ & - & $19.57 \% \uparrow$ & $0.46 \% \downarrow$ & - \\
\hline & 3rd layer & $80.39 \% \uparrow$ & - & $18.93 \% \downarrow$ & $0.68 \% \uparrow$ & - \\
\hline & 4th layer & $79.38 \% \downarrow$ & - & $20.27 \% \uparrow$ & $0.35 \% \downarrow$ & - \\
\hline \multirow{4}{*}{3} & 1st layer & $82.69 \% \uparrow$ & - & $16.86 \% \downarrow$ & $0.44 \% \downarrow$ & - \\
\hline & 2nd layer & $82.35 \% \uparrow$ & - & $17.20 \% \downarrow$ & $0.46 \% \downarrow$ & - \\
\hline & 3rd layer & $78.58 \% \downarrow$ & - & $20.89 \% \uparrow$ & $0.53 \% \uparrow$ & - \\
\hline & 4th layer & $77.35 \% \downarrow$ & - & $21.99 \% \uparrow$ & $0.65 \% \uparrow$ & - \\
\hline \multirow{5}{*}{12} & 1st layer & $81.26 \% \uparrow$ & - & $18.32 \% \downarrow$ & $0.42 \% \downarrow$ & - \\
\hline & 2nd layer & $80.57 \% \uparrow$ & - & $18.96 \% \downarrow$ & $0.47 \% \downarrow$ & - \\
\hline & & & & & & \\
\hline & 3rd layer & $79.94 \% \downarrow$ & - & $19.58 \% \uparrow$ & $0.48 \% \downarrow$ & - \\
\hline & 4th layer & $77.18 \% \downarrow$ & - & $22.27 \% \uparrow$ & $0.55 \% \uparrow$ & - \\
\hline
\end{tabular}

Note: arrows indicate the changes in the proportions compared with initial values before test. 
Table 11 Values of coefficient $\alpha$ for various clogging tests

\begin{tabular}{|c|c|c|c|c|c|c|}
\hline Cases & Coefficient $\alpha$ & $P$ & $H$ & $D_{\mathrm{r}}$ & $R_{\mathrm{s}}$ & $C_{\mathrm{u}}$ \\
\hline & 2.77 & & & & & \\
\hline \multirow[t]{3}{*}{1} & 3.51 & 0.15 & 4 & 0.6 & 7.37 & 10.16 \\
\hline & 3.72 & & & & & \\
\hline & 3.66 & & & & & \\
\hline \multirow[t]{3}{*}{2} & 3.45 & 0.20 & 4 & 0.6 & 7.21 & 10.16 \\
\hline & 4.03 & & & & & \\
\hline & 4.96 & & & & & \\
\hline \multirow[t]{3}{*}{3} & 4.21 & 0.25 & 4 & 0.6 & 7.06 & 10.16 \\
\hline & 3.98 & & & & & \\
\hline & 4.52 & & & & & \\
\hline \multirow[t]{3}{*}{4} & 4.13 & 0.25 & 4 & 0.6 & 3.41 & 10.45 \\
\hline & 3.78 & & & & & \\
\hline & 4.77 & & & & & \\
\hline \multirow[t]{3}{*}{5} & 4.56 & 0.25 & 4 & 0.6 & 13.41 & 17.26 \\
\hline & 4.36 & & & & & \\
\hline & 4.02 & & & & & \\
\hline \multirow[t]{3}{*}{6} & 4.75 & 0.25 & 4 & 0.6 & 28.25 & 33.73 \\
\hline & 5.53 & & & & & \\
\hline & 5.04 & & & & & \\
\hline \multirow[t]{3}{*}{7} & 4.53 & 0.25 & 4 & 0.6 & 7.06 & 11.05 \\
\hline & 3.66 & & & & & \\
\hline & 5.07 & & & & & \\
\hline \multirow[t]{3}{*}{8} & 4.25 & 0.25 & 4 & 0.6 & 7.06 & 10.01 \\
\hline & 3.52 & & & & & \\
\hline & 5.26 & & & & & \\
\hline \multirow[t]{3}{*}{9} & 6.33 & 0.25 & 4 & 0.3 & 7.06 & 10.16 \\
\hline & 6.75 & & & & & \\
\hline & 3.88 & & & & & \\
\hline \multirow[t]{3}{*}{10} & 3.51 & 0.25 & 4 & 0.9 & 7.06 & 10.16 \\
\hline & 3.96 & & & & & \\
\hline & 5.93 & & & & & \\
\hline \multirow[t]{3}{*}{11} & 5.24 & 0.25 & 3 & 0.6 & 7.06 & 10.16 \\
\hline & 4.79 & & & & & \\
\hline & 3.83 & & & & & \\
\hline \multirow[t]{3}{*}{12} & 3.27 & 0.25 & 5 & 0.6 & 7.06 & 10.16 \\
\hline & 2.95 & & & & & \\
\hline & 5.97 & & & & & \\
\hline 13 & 5.84 & 0.15 & 3 & 0.3 & 3.56 & 10.45 \\
\hline
\end{tabular}

https://mc06.manuscriptcentral.com/cgj-pubs 


\begin{tabular}{llllllll} 
& 5.72 & & & & & \\
14 & 4.03 & & & & & & \\
& 3.85 & 0.15 & 5 & 0.9 & 13.98 & 17.26 \\
& 4.08 & & & & & \\
& 5.86 & & & & & \\
15 & 5.97 & 0.2 & 5 & 0.6 & 3.48 & 10.45 \\
& 5.48 & & & & & \\
& 3.19 & & & & & \\
16 & 2.85 & 0.2 & 3 & 0.9 & 7.21 & 10.16 \\
& 3.06 & & & & & \\
& 6.02 & & & & & \\
17 & 5.59 & 0.2 & 4 & 0.3 & 13.69 & 17.26 \\
& 5.86 & & & & & \\
& 4.68 & & & & & \\
18 & 4.35 & 0.25 & 4 & 0.9 & 3.41 & 10.45 \\
& 4.52 & & & & & \\
& 6.24 & & & & & \\
\multirow{4}{*}{19} & 6.18 & 0.25 & 5 & 0.3 & 7.06 & 10.16 \\
& 5.87 & & & & & \\
& 3.93 & & & & & \\
& 3.99 & 0.25 & 3 & 0.6 & 13.41 & 17.26 \\
& 4.14 & & & & & \\
\hline
\end{tabular}

https://mc06.manuscriptcentral.com/cgj-pubs 
Table 12 Equivalent characteristic sizes of solid grain in pervious concrete

\begin{tabular}{ccccccc}
\hline$P$ & $R_{\mathrm{v}}$ & $R_{\mathrm{d}}$ & $D_{10}$ & $D_{15}$ & $D_{60}$ & $D_{85}$ \\
& & & $(\mathrm{~mm})$ & $(\mathrm{mm})$ & $(\mathrm{mm})$ & $(\mathrm{mm})$ \\
\hline $15 \%$ & 1.40 & 1.12 & 7.93 & 8.25 & 10.38 & 11.58 \\
$20 \%$ & 1.31 & 1.10 & 7.77 & 8.08 & 10.17 & 11.35 \\
$25 \%$ & 1.23 & 1.07 & 7.60 & 7.91 & 9.96 & 11.11 \\
\hline
\end{tabular}


Table 13 Characteristic sizes of clogging materials

\begin{tabular}{ccccc}
\hline Clogging & $d_{10}$ & $d_{15}$ & $d_{60}$ & $d_{85}$ \\
materials & $(\mathrm{mm})$ & $(\mathrm{mm})$ & $(\mathrm{mm})$ & $(\mathrm{mm})$ \\
\hline M1 & 0.24 & 0.28 & 1.17 & 2.32 \\
M2 & 0.68 & 0.71 & 0.92 & 1.12 \\
M3 & 0.32 & 0.33 & 0.47 & 0.59 \\
M4 & 0.15 & 0.16 & 0.25 & 0.28 \\
\hline
\end{tabular}


Table 14 Values of hydraulic conductivity of sand column for various clogging tests

\begin{tabular}{|c|c|c|c|c|c|c|}
\hline Cases & $k_{\mathrm{s}} / k_{\mathrm{s} 0}$ & $P$ & $H$ & $D_{\mathrm{r}}$ & $R_{\mathrm{s}}$ & $C_{\mathrm{u}}$ \\
\hline & 0.23 & & & & & \\
\hline \multirow[t]{3}{*}{1} & 0.28 & 0.15 & 4 & 0.6 & 7.37 & 10.16 \\
\hline & 0.36 & & & & & \\
\hline & 0.44 & & & & & \\
\hline \multirow[t]{3}{*}{2} & 0.55 & 0.20 & 4 & 0.6 & 7.21 & 10.16 \\
\hline & 0.48 & & & & & \\
\hline & 0.51 & & & & & \\
\hline \multirow[t]{3}{*}{3} & 0.41 & 0.25 & 4 & 0.6 & 7.06 & 10.16 \\
\hline & 0.37 & & & & & \\
\hline & 0.36 & & & & & \\
\hline \multirow[t]{3}{*}{4} & 0.29 & 0.25 & 4 & 0.6 & 3.41 & 10.45 \\
\hline & 0.24 & & & & & \\
\hline & 0.72 & & & & & \\
\hline \multirow[t]{3}{*}{5} & 0.99 & 0.25 & 4 & 0.6 & 13.41 & 17.26 \\
\hline & 0.87 & & & & & \\
\hline & 1.21 & & & & & \\
\hline \multirow[t]{3}{*}{6} & 1.15 & 0.25 & 4 & 0.6 & 28.25 & 33.73 \\
\hline & 1.32 & & & & & \\
\hline & 0.42 & & & & & \\
\hline \multirow[t]{3}{*}{7} & 0.64 & 0.25 & 4 & 0.6 & 7.06 & 11.05 \\
\hline & 0.53 & & & & & \\
\hline & 0.32 & & & & & \\
\hline \multirow[t]{3}{*}{8} & 0.28 & 0.25 & 4 & 0.6 & 7.06 & 10.01 \\
\hline & 0.38 & & & & & \\
\hline & 0.31 & & & & & \\
\hline \multirow[t]{3}{*}{9} & 0.34 & 0.25 & 4 & 0.3 & 7.06 & 10.16 \\
\hline & 0.41 & & & & & \\
\hline & 0.39 & & & & & \\
\hline \multirow[t]{3}{*}{10} & 0.62 & 0.25 & 4 & 0.9 & 7.06 & 10.16 \\
\hline & 0.47 & & & & & \\
\hline & 0.72 & & & & & \\
\hline \multirow[t]{3}{*}{11} & 0.68 & 0.25 & 3 & 0.6 & 7.06 & 10.16 \\
\hline & 0.57 & & & & & \\
\hline & 0.29 & & & & & \\
\hline \multirow[t]{3}{*}{12} & 0.23 & 0.25 & 5 & 0.6 & 7.06 & 10.16 \\
\hline & 0.33 & & & & & \\
\hline & 0.31 & & & & & \\
\hline 13 & 0.22 & 0.15 & 3 & 0.3 & 3.56 & 10.45 \\
\hline
\end{tabular}




\begin{tabular}{|c|c|c|c|c|c|c|}
\hline \multicolumn{7}{|c|}{0.35} \\
\hline & 0.41 & & & & & \\
\hline \multirow[t]{3}{*}{14} & 0.56 & 0.15 & 5 & 0.9 & 13.98 & 17.26 \\
\hline & 0.61 & & & & & \\
\hline & 0.29 & & & & & \\
\hline \multirow[t]{3}{*}{15} & 0.22 & 0.2 & 5 & 0.6 & 3.48 & 10.45 \\
\hline & 0.31 & & & & & \\
\hline & 0.74 & & & & & \\
\hline \multirow[t]{3}{*}{16} & 0.65 & 0.2 & 3 & 0.9 & 7.21 & 10.16 \\
\hline & 0.82 & & & & & \\
\hline & 0.55 & & & & & \\
\hline \multirow[t]{3}{*}{17} & 0.51 & 0.2 & 4 & 0.3 & 13.69 & 17.26 \\
\hline & 0.64 & & & & & \\
\hline & 0.32 & & & & & \\
\hline \multirow[t]{3}{*}{18} & 0.29 & 0.25 & 4 & 0.9 & 3.41 & 10.45 \\
\hline & 0.49 & & & & & \\
\hline & 0.28 & & & & & \\
\hline \multirow[t]{3}{*}{19} & 0.43 & 0.25 & 5 & 0.3 & 7.06 & 10.16 \\
\hline & 0.39 & & & & & \\
\hline & 0.87 & & & & & \\
\hline \multirow[t]{2}{*}{20} & 0.95 & 0.25 & 3 & 0.6 & 13.41 & 17.26 \\
\hline & 0.93 & & & & & \\
\hline
\end{tabular}

https://mc06.manuscriptcentral.com/cgj-pubs 